\title{
MOLINOS ACEITEROS EN MONTEFRÍO (GRANADA): EVOLUCIÓN Y PROPIETARIOS DESDE EL SIGLO XVIII HASTA MEDIADOS DEL SIGLO XX ${ }^{1}$
}

\author{
Oil Mills in Montefrío (Granada): Evolution and Owners from \\ the $18^{\text {th }}$ Century to the Middle of the $20^{\text {th }}$ Century
}

\author{
Rafael J. Pedregosa Megías \\ rpedregosam@gmail.com \\ HistoriadorArqueólogo. España \\ Felipe Jiménez Comino \\ felipe@montefrio.org \\ Ayuntamiento de Montefrío. España \\ Fecha de recepción: 14/05/2020 \\ Fecha de aceptación: 28/09/2020
}

Resumen: Montefrío es un caso paradigmático ya que, desde la conquista de la villa nazarí por los Reyes Católicos en 1486, fue nombrada una de las siete villas que abastecerán de cereal, principalmente trigo a la capital Granada. Desde esas fechas se extendió el cereal por el amplio término municipal de $254 \mathrm{~km}^{2}$, acompañado de la ganadería en las zonas de dehesa del municipio. Será a partir del siglo XVIII cuando surjan los primeros molinos de aceite documentados en el Catastro de Ensenada. Durante el siglo XIX se producirá un aumento de la extensión del olivar en Montefrío, como consecuencia de las diversas reformas agrarias que tendrán lugar en estos momentos. Este hecho provocará un mayor número de campesinos que accederán a la tierra, y, por tanto, una mayor extensión de hectáreas dedicadas al cultivo del olivo, en consecuencia,

1 Trabajo expuesto en las Segundas Jornadas del Avula-Biblioteca del Olivar. Celebradas el 10 de noviembre de 2018 en la Real Academia de Antequera. Organizadas por el Dpto. de Filología Española, Italiana, Románica, Teoría de la Literatura y Literatura Comparada Real Academia de Antequera. Estas jornadas no serán publicadas. 
un aumento del número de almazaras y fábricas de aceite por todo el término municipal. A continuación, analizamos la evolución de los molinos aceiteros y sus propietarios desde el siglo XVIII hasta mediados del siglo XX. Para ello utilizaremos varias fuentes de información: el Catastro del Marqués de la Ensenada, Madoz, los Padrones de Riqueza y de Vecinos conservados en el Ayuntamiento de Montefrío, la información oral y la del registro de la propiedad. A ello unimos la información procedente de los restos y molinos conservados de este tipo de industria localizados en el municipio.

Palabras clave: Montefrío; propietarios; molinos de aceite; prensa de viga; prensa de torre; prensa hidráulica.

Abstract: Montefrío is a paradigmatic case because, since the conquest of the Nasrid village by the Catholic Monarchs in 1486, it was named one of the seven towns that will supply cereal, mainly wheat to the capital Granada. From those times the cereal was extended by the ample municipal area of $254 \mathrm{~km}^{2}$, accompanied by the cattle ranch in the zones of dehesa of the municipality. It was in the 18th century that the first oil mills, documented in the Ensenada Cadastre, appeared. During the nineteenth century there was an increase in the extension of olive groves in Montefrío, as a result of the various agrarian reformations that took place at this time. This fact will provoke a greater number of peasants that will accede to the fields, and therefore, a greater extension of hectare analyse the evolution of the oil mills and their owners from the 18th cents dedicated to the culture of the olive tree, consequently, an increase of the number of oil mills and factories of oil by all the municipal term. Next, we analyse the evolution of the oil mills and their owners from the 18th century to the middle of the 20th century. For this we will use several sources of information: the Cadastre of Ensenada, Madoz, wealth and neighbourhood registers conserved in the Town Hall of Montefrío, the oral information and that of the property register. For it we join the information coming from the remains and conserved mills of this type of industry located in the municipe.

Keywords: Montefrío; owners; oil mills; beam press; tower press; hydraulic press.

SUMARIO: 1. Introducción. 2. La elaboración del aceite 3. Los molinos y fábricas de aceite en montefrío. 3.1. Molinos en calle Las Marquesas. 3.2. Fábrica de aceite conocida como San Mauricio en el Pósito. 3.3. Fábrica de aceite en calle Muro, Lucas Peña. 3.4. Molino aceitero en callejón Lucas Peña-Paseo. 3.5. Molino aceitero en Calle Alta, 93 (molino de Laureano o Ramírez). 3.6. Fábrica de aceite en la Placeta del Convento, antiguo convento hospicio de la orden San Francisco dedicados a la Observancia. 3.7. El molino de San Cristóbal. 3.8. El molino y fábrica de aceite la Cueva, la Tranca y la Enrea. 3.9. El molino de aceite las Talas (conocido también como de las Manillas). 3.10. Molino de aceite El Cortijuelo. 3.11. Fábrica de aceite Las Angosturas. 3.12. Fábrica de aceite Alcubilla-Tenerías. 3.13. Molino de aceite Cortijo del Perú (molino Entrena). 3.14. Molino aceitero Fuente del Moral. 3.15. Molino de aceite Casería «La Jimena». 3.16. Fábrica de aceite Los Endrinales. 3.17. Molino Venta del Conejo (inicialmente se denominó fábrica de aceites San Francisco). 3.18. Molino del cortijo de la Torre del Sol. 4. A modo de conclusión: molinos y propietarios. 5. Referencias biliográficas. 


\section{INTRODUCCIÓN}

La importancia del olivar en Montefrío fue escasa hasta bien entrado el siglo XVIII. Anteriormente tan solo contamos con alguna mención a olivos dispersos y como complemento al resto de la vida agrícola que dependía del cultivo del cereal y de la ganadería, como consecuencia de la política empleada por los Reyes Católicos tras la conquista de la villa, convirtiéndola en una de las siete villas que abastecerán de trigo a Granada (Peinado, 1997). A mediados del siglo XVIII (1755) tenemos constancia de la venta de hazas con diferentes olivos, 22 fanegas de tierra, en el término de la villa de Montefrío llamadas de Parpajo (¿Dornajo?) que fueron vendidas por Pedro de Molina Berdejo, vecino de la villa de Montefrío a la Abadía del Sacro Monte (Granada). Las tierras fueron vendidas el 29 de abril de 1785 a otro montefrieño, Don Martín Mellado, y fueron compradas posteriormente, el 1 de marzo de 1791, por Francisco Moreno Quadros vecino de la villa de Montefrío (Padilla y Pedregosa, 2013, p. 302; fol. 274r).

El plantío de olivos en este período estaba asociado a zonas de huertas y tierras de secano, compartiendo el cultivo con los cereales, la huerta e incluso las viñas como es el caso del Barranco de las Caleras (Peinado, 1997, p. 87). En estos momentos, el peso de la agricultura superaba al de la industria, y a la transformación y manufacturación de los productos agrícolas como el cereal (trigo-pan) y el olivar (aceituna-aceite). Este fenómeno ya destaca en la información de Ensenada, que menciona 6 molinos harineros (Pedregosa y Jiménez, 2013, Pedregosa, 2017) frente a 2 aceiteros a mediados del siglo XVIII (Peinado, 1997).

El profesor Peinado, en su estudio del Catastro de Ensenada, recoge que se podía comprar el aceite en una de las panaderías y en las 8 tabernas que existían en Montefrío, mientras abundaban las panaderías con un total de 22 (Peinado, 1997, p. 45), una vez más se evidenciaba el peso del cereal en las tierras y campos de Montefrío.

A mediados del siglo XVIII, concretamente en 1752, como se ha comentado, tenemos la constancia de la existencia de dos molinos aceiteros en Montefrío, según el Catastro de Ensenada (Peinado, 1997, p. 78,81). En la pregunta 17 ¿Si hay algunas Minas, Salinas, Molinos Harineros, o de papel, Batanes, u otros artefactos en el Término, distinguiendo de qué Metales, y de qué uso, explicando sus Dueños, y lo que se regula, ¿produce cada uno de utilidad al año?

$\mathrm{Y}$, asimismo, ay en esta villa dos molinos de aceite en los ruedos de ella:

- El uno, de doña María Ramírez, vecina de ella, que le producirá cinquenta ducados de utilidad cada año, unos con otros;

- Y el otro es de dicho Juan de Rabaneda, que le producirá, en la misma forma la utilidad cada año, otros cinquenta ducados.

En relación, al segundo molino propiedad de Juan de Rabaneda, el Vecindario Secular referente a Montefrío (1411), fechado el 10 de mayo de 1753, aporta más datos del molino de aceite: 
Un molino de azeite nombrado el Molino del Huerto de la Blanca. Está ynmediato a la población, tiene 15 baras en cuadro. Con sus trojes y patio. Esta yslado en tierras de riego de esta hacienda y según las respuestas generales tiene de utilidad en dicho molino por sus moliendas 550 reales de vellón².

Según el catastro de Ensenada en 1750 las almazaras o molinos de aceite de Montefrío contaban con prensas de viga ${ }^{3}$, la de San Cristóbal y la de la Tranca (Cueva o Enrea), o el posterior del siglo XIX ubicado en Las Talas. Este tipo de molinos eran similares en sus sistemas de prensado al de la almazara de Las Laerillas en Nigüelas (Granada), un molino de prensa «de viga y quintal» que data de finales del siglo $\mathrm{xV}$ principios de la centuria siguiente, aunque su origen puede remontarse al siglo XIII, y las almazaras cordobesas.

Parece, por los datos que tenemos, que estos dos molinos de aceite citados en el Catastro de Ensenada se ubicarían en las inmediaciones del núcleo urbano de Montefrío, en las tierras cercanas al mismo, que se denominaban ruedos (Tierras o heredades que están situadas en los alrededores de una ciudad. En el olivar, labor al suelo bajo la copa del árbol que se hace para facilitar la recolección). Estos molinos serían el de la Tranca, donde se encuentra el molino de la Cueva-Enrea, y el ubicado en la huerta de la Capellanía, en la que se ubicaría una antigua Tercia (Casa en que se depositaban los diezmos) perteneciente a los monjes franciscanos ubicados en la zona de Montefrío desde el siglo XVI, de la Orden de San Francisco. Tras la desamortización surgirá el molino de San Cristóbal, que aún hoy perdura en funcionamiento como fábrica de aceite.

En el siglo XVIII todavía el peso del cereal era muy importante prueba de ello son la gran cantidad de molinos hidráulicos de cereal que existían en Montefrío a lo largo del siglo XVIII y el XIX, con un origen a finales del siglo XV y principios del siglo XVI (Pedregosa y Jiménez, 2013, Pedregosa, 2017). Otro factor que influye en el reducido peso del olivar era la gran extensión de tierras dedicadas al cereal, siendo el olivar disperso, entre zonas de cereal y poco antropizado (Infante, 2011, p. 101). Este hecho era consecuencia del pasado histórico de la villa de Montefrío, denomi-

2 AHPG, Archivo Histórico Provincial de Granada. Vecindario secular (Montefrío-1411) Fecha:10/5/1753 fol. 0109-v.

3 Para el funcionamiento de las prensas de viga y su composición Ver: S. Pizarro, "La Almazara de las Laerillas» en AAVV: La almazara de Las Laerillas Nigüelas. Patrimonio industrial del valle de Lecrín, Granada, 2015, págs., 58-82. A. Moreno Vega y Mạ. Y. López Gálvez, «Del siglo XVI al XVIII en las almazaras cordobesas del sur: génesis, auge y declive de los grandes molinos ducales». XIV Congreso de Historia Agraria, 2013, Badajoz 7-9 noviembre. [Consulta 14 noviembre de 2018 http://seha.info/congresos/articulos/A.3.\%20Moreno\%20y\%20L\%C3\%B3pez.pdf], M. Y. López, F. Montes, E. Burgos y A. Moreno, «Análisis tecnológico-funcional y arquitectónico de las almazaras cordobesas en la Edad Moderna». Separata ITEA, Información Técnica Económica Agraria, Vol. 108 , № 3, 2012, págs. 312-342. 
nada como una de las "siete villas» que abastecían de cereal a la capital, unido al hecho de una gran cabaña y al aprovechamiento de la ganadería. Granada ejercía el poder sobre las siete villas de Los Montes, garantizando el aprovisionamiento cerealista y cárnico de la ciudad (que «tiene más población que ningún lugar de estos reynos y es vna de las prinçipales çibdades que ay en todos los reynos»), pues La Vega solo daba para mantener a una sexta parte de sus habitantes (Peinado, 1997, p. 27).

La economía en Montefrío en el siglo XVIII se basaba principalmente en el campo, 9 de cada 10 reales procedían del mismo, donde destacaba la producción de trigo. El viñedo y el olivo ocupaban en estos momentos una parte insignificante del suelo, aunque el olivar estaba en expansión como consecuencia de la reducción de la cabaña ganadera, unido a las roturaciones de terreno y al uso de abonos inorgánicos (Peinado, 1997, pp. 41-42). Era frecuente en estos momentos, encontrar estacas de olivar plantadas en tierras del común o en bienes de propios (Infante, 2011, p. 151).

A partir del primer tercio del siglo XIX, el aumento demográfico y el reparto de tierras como consecuencia de las distintas reformas y procesos desamortizadores ocurridos provocarán la colonización del campo, ampliando las zonas de cultivo cercanas al municipio (Martínez, 1995).

A mediados del siglo XIX tenemos más información acerca de los molinos aceiteros existentes en Montefrío gracias a Pascual Madoz. En su obra recoge la existencia de un molino en las Angosturas, pertenecientes al partido de las Huertas (inmediato y en torno a la población). También menciona otro molino aceitero en el partido de las Talas. «En estos momentos Montefrío producía unas 40000 arrobas de aceite». Incluso Madoz aporta la tipología y el número total de molinos aceiteros existentes en el término de Montefrío; menciona 7 molinos de aceite, 2 de dos vigas, 1 de una viga y 4 de prensa de torrecilla (Madoz, 1848, p. 540). A partir de los datos obtenidos sobre los distintos molinos, sabemos que, a parte de los molinos nombrados directamente por Madoz, el de las Talas (prensa de viga) y las Angosturas (Torrecilla), los otros cinco eran el de la Tranca (prensa de viga/torrecilla), El Cortijuelo (Prensa de Torrecilla), La Fuente del Moral (P. Torrecilla), y los ubicados en el casco urbano en calle Enrique Amat 93 (P. Viga) y el de callejón de Muro (P. Torrecilla).

En torno a 1850 destacaban los olivares en la zona conocida como Los Gitanos (Madoz, 1848, p. 540), además de los de la Cuesta del Aceite cerca de las Angosturas, así como otros olivares y zonas productoras del olivar, que son recogidas en la obra de Juan Infante (Infante, en prensa).

Entre mediados del siglo XVIII y el siglo XIX Montefrío se caracterizaba por el "olivar campal» con tan solo 2000 pies de olivo, insertos entre hortalizas o cereal, también entre álamos, frutales y moreras (Infante, 2011, p. 135). El olivo en estos momentos siempre estuvo vinculado a la pequeña propiedad. A finales del siglo XIX, 
hasta el primer tercio del siglo XX, Montefrío multiplico la superficie de olivar por hectárea, de 100 ha en 1750 a más de 700 ha en 1900 (Infante, 2011, p. 236), fenómeno que provocaría la nueva a aparición de ingenios y almazaras en este período.

En la evolución de molinos y fábricas de aceite en Montefrío influyó el desarroIlo del olivar, desde mediados del siglo XVIII en adelante, con el cultivo de la rotación al tercio y el olivar campal, frente a los cambios que se producirán en el siglo XX, con un cultivo del olivar ordenado y en solitario, aunque asociado a otros cultivos, aumentando la extensión en hectáreas y el olivar intensivo actual. En la evolución del mismo tendrá mucho que ver el aumento demográfico y la colonización del amplio término municipal de Montefrío con la diseminación de cortijos (Infante, en prensa).

La mayoría de los molinos que veremos a continuación ya estarían en funcionamiento a mediados del siglo XIX. Estos sufrirán cambios tanto en su maquinaria y elementos de prensado como la molturación de la aceituna, adaptándose a los tiempos, así como en su propiedad y titularidad al ser posteriormente arrendados, pasando de unos a otros.

La molturación de la aceituna no sufrió demasiados cambios; desde mediados del siglo XVIII se realizaba con piedras cilíndricas que fueron sustituyéndose a finales del siglo XIX y el Xx por piedras troncocónicas o rulos, con el prensado realizado con capachos, que perduraron hasta mediados del siglo Xx, abandonándose al introducir el sistema continuo.

El sistema de prensando irá evolucionando; desde finales del siglo XIX y provocará la sustitución de las prensas de viga por las de husillo ya que eran mucho más rentables, produciendo el doble de aceite que las anteriores y haciendo más eficaz y rápido el proceso de molienda, lo que permitía reducir el tiempo de almacenamiento de la aceituna, con el consiguiente aumento de la calidad del aceite. Este almacenamiento, que tradicionalmente se llevaba a cabo en los trojes o atrojes (que consistían en un espacio limitado por tabiques, para guardar frutos y especialmente cereales, o aceitunas) documentados en la mayoría de los molinos de Montefrío, dejará de utilizarse a lo largo del siglo $\mathrm{xx}$, debido especialmente al abandono del sistema de maquila (era el pago, generalmente en especie, que cada cosechero hacía al molinero por la molienda de su aceituna, llevándose a su vez el aceite producido por la misma para sus necesidades). Este sistema dejó de tener sentido cuando la producción individual de cada uno superaba con creces esta necesidad de aceite para autoconsumo, siendo más eficaz y práctica la comercialización de dicho exceso por el molinero que por cada uno de los cosecheros individualmente) y al problema de la pérdida de calidad del aceite provocado por los largos tiempos de espera del fruto antes de ser molturado (Zambrana, 1987, p. 138).

Algunos de los molinos cambiarían sus instalaciones de prensando y molturación; este sería el caso de las almazaras de calle de las Marquesas, calle Muro/ 
Lucas Peña o la fábrica ubicada en Paseo/Lucas Peña, que adaptarán su maquinaria a los nuevos tiempos. Aunque las nuevas prensas iban evolucionando, no todos los molinos se adaptaron a la modernidad, y algunos con retraso, este sería el caso de los molinos de Las Angosturas y El Cortijuelo, que seguían manteniendo prensas de torre, que acabarían desapareciendo en la década de 1940. A partir de la década de 1920, se empezarán a instalar prensas hidráulicas en molinos como el del Zanjón, Los Endrinales, La Casería Jimena, el Perú, La Alcubilla, El Pósito, El Convento, La Fuente del Moral, y a lo largo de la década siguiente estaría prácticamente en todos los molinos que seguían en funcionamiento. En la década de 1930 la mayoría de las prensas empleadas eran las hidráulicas, en Montefrío tan solo dos seguirían usando la prensa de husillo, la situada en la calle de las Marquesas y la de calle Muro Lucas Peña.

Prácticamente todas las almazaras y fábricas de aceite se adaptaron a los cambios y adoptaron las prensas hidráulicas hasta abandonarse la mayoría de ellos en los años 50 y 60 del pasado siglo, ante la proliferación del sistema continuo de molturación de la aceituna y el asociacionismo y la creación de las cooperativas de productores; este sería el caso de la cooperativa de San Francisco de Asís, y la tardía aparición de la Fábrica de aceite de El Mármol.

\section{LA ELABORACIÓN DEL ACEITE}

Para la elaboración de aceite en las fábricas o molinos, el proceso comenzaba con el acopio de la misma a las instalaciones en el molino, quedando está en distintos compartimentos llamados trojes o algorines, en los que se depositaba la aceituna de cada agricultor o cosechero por orden de llegada, para su molienda.

Una vez la aceituna en el molino y limpia, se transportaba a la sala de molienda para su trituración, en el empiedro constituido por la solera y el alfarje, que consistía en una estructura circular de piedra, normalmente de granito o caliza, aunque en Montefrío destacó un empidro denominado salipé (una variedad de granito específico para la trituración de la aceituna), sobre la que giraba la llamada piedra corredera, de forma troncocónica, que se movía alrededor de un árbol llamado peón, impulsado por tracción animal o humana, como en el caso del molino ubicado en la calle Enrique Amat 93, o por un molino hidráulico como el Molino de las Talas. En los primeros momentos las piedras eran cilíndricas, aunque estas fueron sustituidas por rulos troncocónicos en los molinos montefrieños, que debieron sustituirse a finales del siglo XIX o en las primeras décadas del siglo XX, como indica Zambrana para las almazaras andaluzas (Zambrana, 1987, pp. 138-145). La molienda no duraba más de 30 minutos, para no romper el hueso de la aceituna y estropear la calidad del aceite siendo amargo, tampoco era bueno una molienda lenta, ya que producía acidez. En el proceso de molienda era destacable la figura 
del garrafador, que se encargaba de verter la aceituna al empiedro para ser molida (López et al., 2012, p. 315).

Obtenido el aceite, ya fuera de la primera prensada en frío, de la segunda o tercera con agua caliente, este era trasvasado de la regaifa por unos conductos hasta distintas piletas o pozuelos, para su posterior decantación y separación del alpechín, finalizando el trasiego del mismo hasta las tinajas, pasando el alpechín por distintos conductos hasta las alpechineras (López et al., 2012, p. 320). Tras este proceso, el aceite era trasladado a tinajas en la bodega. El aceite era extraído de los pocillos o pozuelos a tinajas de barro, incrustadas en el suelo y las paredes de la bodega, colocadas en hileras, evitando la luz y una alta temperatura para no echar a perder sus propiedades (Pizarro, 2015, p. 79; López et al., 2012, pp. 320-321).

Los molinos montefrieños contaban con otro tipo de instalaciones, que veremos después, para el ejercicio de la obtención del acetite. Estas eran cuadras y pajares, destinados a las bestias utilizadas en la molienda de la aceituna, y almacenes para el alimento de los mulos, con alpacas de paja. En las instalaciones eran frecuentes obras hidráulicas como pozos, pilares, fuentes o aljibes, para obtener agua, elemento fundamental en el proceso de obtención del aceite. Un elemento primordial era la caldera, ubicada en la nave de prensado, para evitar una baja temperatura y favorecer el prensado de la pasta oleosa en los cargos colocados en la regaifa, su función era la de calentar el agua para escaldar los capachos. A ello debemos unir las dependencias para los trabajadores o "gañanías», término por el que eran conocidos los mozos o criados que realizaban los trabajos en el molino ${ }^{4}$. A lo largo de la descripción de cada molino veremos las partes que configuraban dichos ingenios a través de la información del catastro y la evolución de los propietarios a partir del registro de la propiedad de Montefrío.

En el siglo XVIII en Montefrío solo existían dos molinos aceiteros, como hemos comentado anteriormente, en los que el prensado se hacía mediante el empleo de prensas de viga y quintal herederos del mundo romano, estos eran el Molino de San Cristóbal y el ubicado en la Tranca, Cueva o Enrea (conocido como molino de la Huerta de la Blanca). A lo largo del siglo XIX, otros molinos adoptarán el sistema de prensa de viga y quintal, como el Molino de las Talas o el ubicado en la calle Enrique Amat 93.

La prensa de viga y quintal se basaba en la presión que ejercía una gran viga formada por varias vigas de madera de pino o encina unidas mediante zunchos de hierro sobre un cargo asentado encima de la regaifa, que consistía en una piedra circular, con un canal en su ontorno, por donde corría el líquido que sale de los capachos llenos de aceituna molida y sometidos a presión. Esta prensa contaba con un husillo también hecho con madera de encina para su funcionamiento, y que

${ }^{4}$ A lo largo de la descripción de los distintos tipos de molinos veremos la estructura y elementos constructivos que formaban parte de los mismos. 
movían normalmente dos operarios con el objetivo de elevar o bajar la piedra de quintal para cargar los capachos (que consisten en un recipiente de esparto apretado, compuesto de dos piezas redondas cosidas por el canto, con un orificio en el centro, que se llenaba de aceituna molida para prensarla: también llamado cofín) en la regaifa y bajar la viga con cuya presión exprimía la pasta de los cargos (pila de capachos llenos de masa de aceituna, colocados sobre la regaifa para ser exprimidos), con el apriete del usillo obteniendo así el líquido que corría por los surcos de la regaifa con destino a los pozuelos de decantación para separar el aceite de los demás residuos, orujo, alpechín. La viga suponía entre un 20-30\% del coste total de la almazara. La cabeza de la viga quedaba fijada en la hornacina del torreón macizo que ejercía de contrapeso (López et al., 2012, pp. 317-318; Pizarro, 2015, pp. 7075).

A partir del siglo XIX, con la evolución del sector olivarero en el municipio de Montefrío, surgirán otros molinos que emplearán para el prensado de la aceituna, la prensa de torrecilla, de ahí que se conozcan como molinos de torre. La denominada prensa de torre o torrecilla; en Montefrío tenemos los molinos de El Cortijuelo (1883), el de la Tranca/Cueva/Enrea, que en algún momento de su existencia utilizó este tipo de prensa, el de las Angosturas (1858) o el de la Fuente del Moral (1883). Al no conservarse restos de este tipo de ingenios desconocemos si la torre era móvil o fija. Las prensas de torre y torrecilla alcanzaron una gran difusión durante la Edad

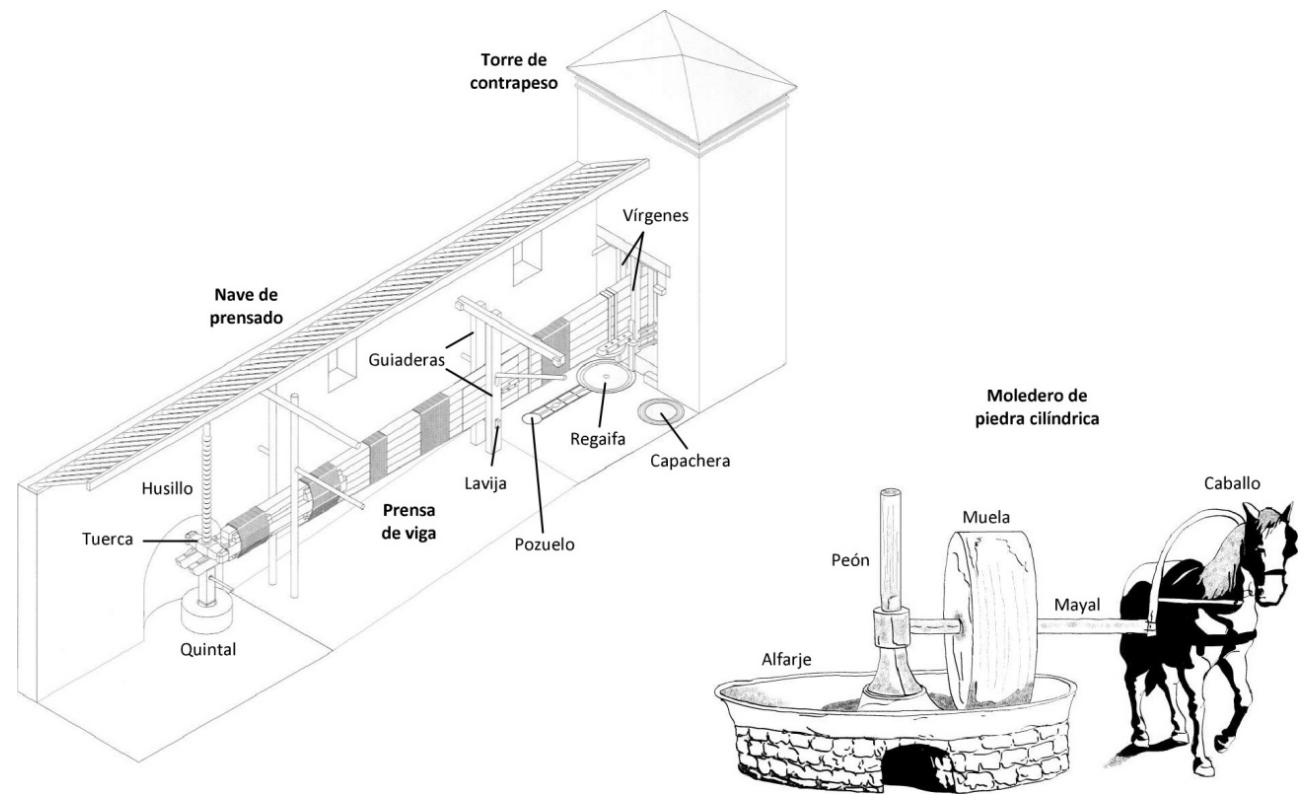

Figura 1. Estructura interior en un molino aceitero con prensa de viga y quintal (Fuente: Moreno y López, 2013, p. 21). 


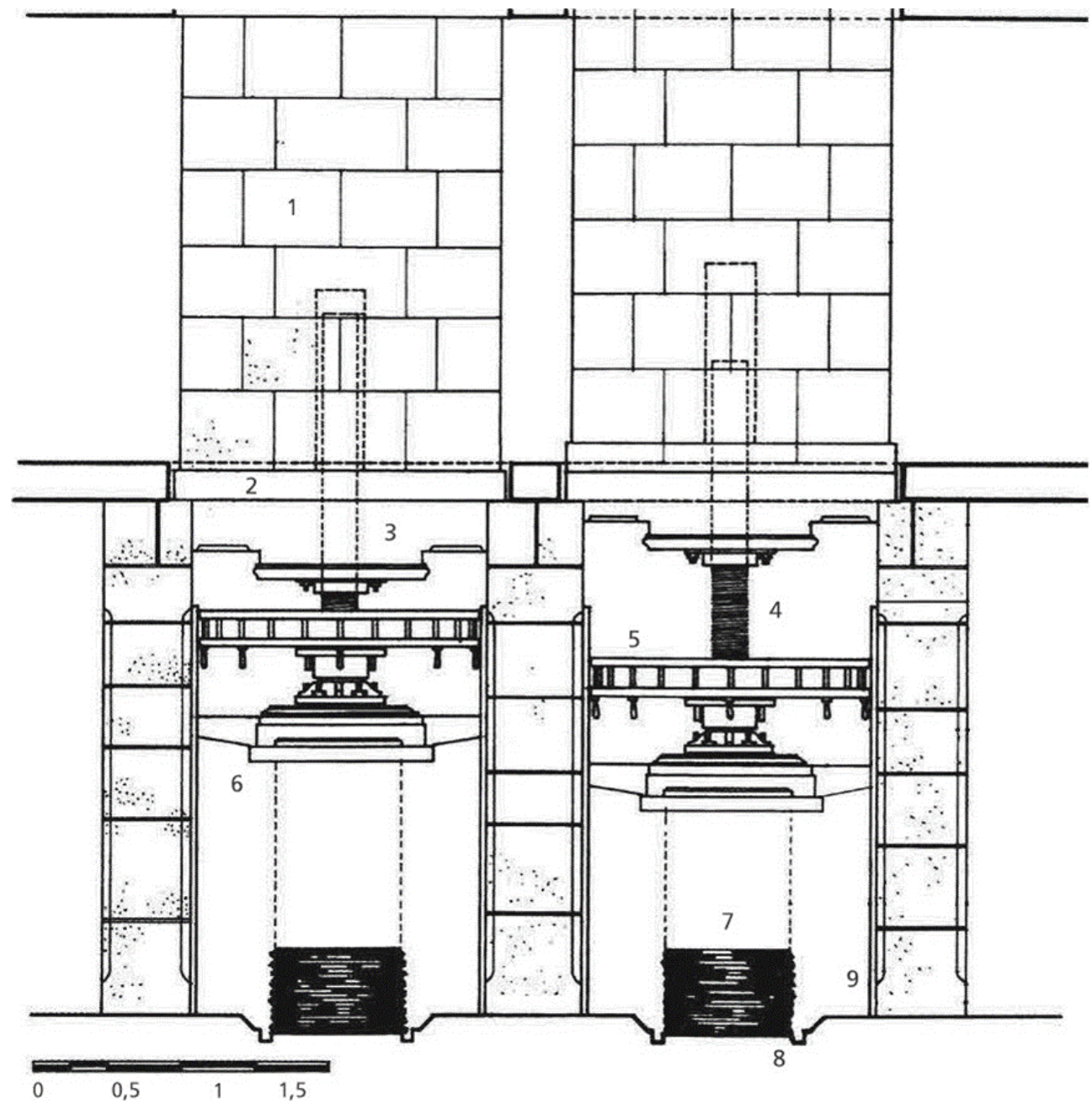

Figura 2. Alzado frontal sobre dos prensas de torrecilla. 1) Torre; 2) base de la torre; 3) tuerca; 4) husillo; 5) cabeza del husillo; 6) marrano; 7) cargo; 8) regaifa; 9) guiadera (Fuente: Eslava Galán, 2004, p. 220).

Moderna en Andalucía por su bajo coste y el poco espacio que ocupaban. Los edificios oleícolas que funcionaban con prensas de torre o torrecilla solían recibir en Andalucía el nombre de molinas, reservando el de molinos para los que albergaron a las prensas de viga (Pequeño, 2010, p. 195).

Las prensas de torre tenían una piedra móvil en dirección vertical y con sentido ascendente o descendente. Para levantar la carga pétrea, usaban un mecanismo compuesto por la combinación de tres elementos de madera: husillo, tuerca y palanca; del cargo, ubicado encima de la regaifa o taza embutida en el suelo, se con- 
seguía dejando caer el macizo de piedra sobre la pasta oleosa. La base de la torre móvil era un armazón de madera que descansaba sobre unos muros perimetrales de piedra, dejando su parte frontal abierta para poder introducir los capachos con la masa de aceituna molida en la cavidad interior que se formaba, denominada capilla. La transmisión del peso de la piedra hacia el cargo se hizo mediante una pieza de madera, llamada marrano, cuya función era distribuir la presión equitativamente sobre todo el volumen de la pasta oleosa. Su limitada capacidad de trabajo hizo que fuesen sustituidas a lo largo del siglo XIX, debido a que era necesario realizar dos prensados del mismo cargo, al no ser muy fuerte la presión, y por tanto la productividad y rendimiento era bajo, por las nuevas prensas industriales (López et al., 2012, pp. 318-320; López, 2013, pp. 82-84), aunque en el caso de Montefrío su sustitución fue más tardía de finales del siglo XIX incluso XX como veremos después. Las prensas de torrecilla presentaban un diseño arquitectónico mucho más sencillo que su homóloga de torre, siendo la única diferencia entre ambas que las primeras, de menor tamaño, solo podían ser vistas desde el interior de la nave donde se ubicaban (López et al., 2012, p. 320; López, 2013, p. 84).
1. Muela o rulo
2. Tolva
3. Árbol
4. Gorrón
5. Rueda catalina
6. Almijarra
7. Alfarje
8. Donpedro
9. Capilla
10. Cargo

11. Husillo

12. Hembra del husillo

13. Cabeza del husillo

14. Marrano o sombrerillo

15. Guiaderas

16. Regaifa

17. Torre

18. Embrague

Molino con prensa

de torre, según Anunciación Carpio.

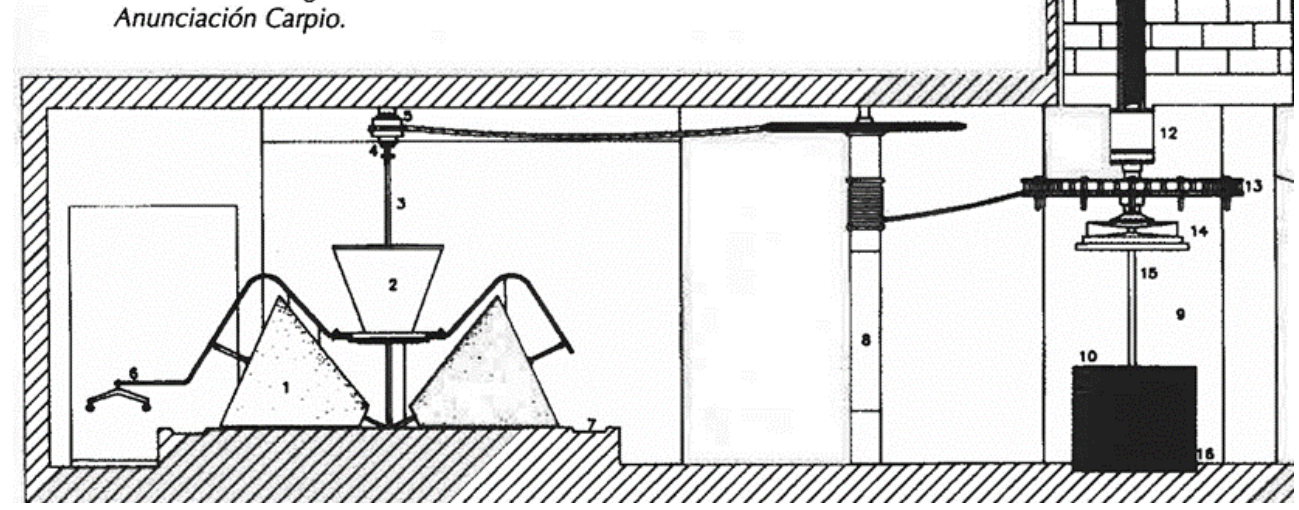

Figura 3. Molino de prensa de torre (Fuente: Eslava Galán, 2004, p. 82). 
A lo largo del siglo XIX se empiezan a introducir nuevas aplicaciones tecnológicas; se pueden citar la sustitución de la muela vertical por los rulos troncocónicos que, al tener mayor superficie, podían molturar más aceituna, la introducción de lavadoras de aceituna, la instalación de prensas de columna y la incorporación paulatina de las prensas hidráulicas de hierro. En estos momentos se pone una importante atención en la limpieza de la aceituna, previa a su molturación para retirar las hojas, ramas y demás impurezas, con el empleo de zarandas o cribas metálicas. Las almazaras fueron incorporando lavadoras de aceituna, unas máquinas que consistían en tornos sumergidos en agua que giraban sobre un eje, como la lavadora hidráulica del industrial Rafael Cisneros en 1863, o la de vapor del sevillano Juan Brieba en Bolillos (Pequeño, 2010, pp. 121-122).

En el prensado de las aceitunas destacaron las prensas de columnas y las prensas hidráulicas. Su antecedente eran las prensas de presión directa mediante husillo vertical centrado, construidas primero en madera y después en hierro (Figura 4). Las prensas de columnas, que estaban fabricadas en hierro, y disponían de un grueso tornillo de rosca que sujetaba en su extremo inferior el platillo de presión con una palanca que era accionada por los operarios para prensar el cargo (Pequeño, 2010, p. 199). Estas prensas solían ocupar una esquina de la almazara, también conocidas como de rincón. En ellas, un tornillo vertical atravesaba una rosca pasante ubicada en el centro de una viga incursada por sus extremos a unos pilares y hierro-madera o a los propios muros de las naves; también llamadas estas prensas de capilla. En algunas prensas, las más potentes, la palanca fue auxiliada por caballería o incluso un cabestrante, para realizar los últimos aprietes. El rendimiento de este tipo de prensas de husillo fue muy reducido al igual que su capacidad productiva.

La prensa de hierro con husillo fue muy usada en el siglo XIX, tenía dos barrotes o columnas, que se unían a un plato circular. El cargo se colocaba sobre una regaifa de hierro, bajo el husillo y el plato y el plato compresor. El movimiento de una barra a través de la fuerza humana producía el prensado de los capachos, al descender el husillo y el plato solidario a él. Estas prensas contaron con manubrios o volantes unidos a los engranajes, estando el plato guiado por cuatro columnas en lugar de dos (Moreno y López, 2017, pp. 100-101).

En Montefrío destacaron molinos que emplearon prensas de husillo, también denominadas de columnas o rincón, en el Molino de Callejón de Muro/Paseo, el molino ubicado en calle Muro/Lucas Peña o el molino ubicado en calle Las Marquesas. La primera prensa hidráulica que se instaló en Andalucía fue la del hacendado Diego de Alvear en su almazara de Montilla en 1834, que fue construida en Manchester. Las ventajas que tenía esta nueva prensa eran enormes: podía prensar 192 fanegas en 24 horas, era más barata que una prensa de viga, ocupaba bastante menos espacio, tenía un rendimiento mayor que aquella, consumía más capachos, aunque su coste se reduce al tener un mayor rendimiento, se podía transportar de 

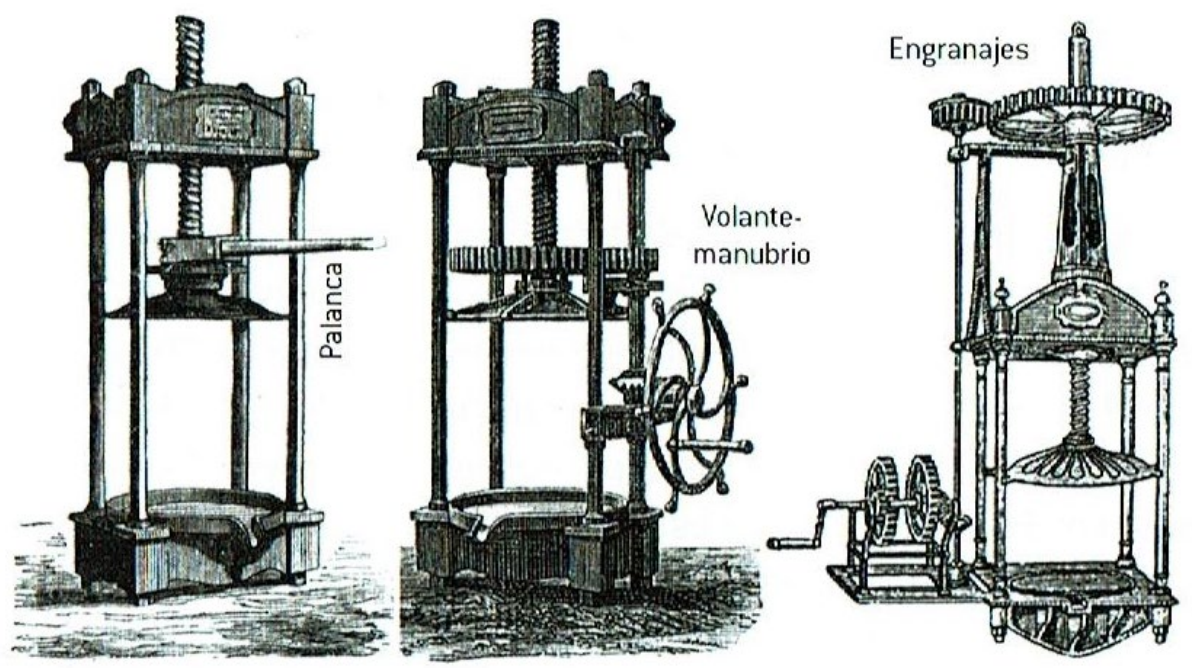

Figura 4. Prensas de husillo de fundición férrea (Fuente: Moreno y López, 2017, p. 102).

un sitio a otro dentro de la almazara y daba mayor cantidad de aceite y de mejor calidad $^{5}$. Las prensas hidráulicas están construidas por un cuerpo de bombas, dentro del mismo se encuentra un cilindro macizo, de fundición o de acero, que sustenta unas planchas sobre cuya superficie se colocan los elementos a prensar. El pistón sube por la inyección de agua por su parte inferior, impulsada mediante una bomba hidráulica (Moreno y López, 2017, p. 106).

En 1870 se introducen las prensas hidráulicas de vapor al mismo tiempo que se experimentaba un aumento de las prensas con husillo tanto de rincón como férreas. Será a finales del s. XIX y principios del s. XX cuando las almazaras modernas dispongan ya de manera generalizada prensas hidráulicas de vapor. En Montefrío el cambio será lento, siendo los primeros molinos en introducir las prensas hidráulicas como en el Convento (1880) o La Casería de La Jimena (1897), aunque la mayoría de ellas se introducirán en la década de 1920, como El Pósito, calle Enrique Amat 93, El Convento, San Cristóbal, Enrea, Las Angosturas, Alcubilla, El Perú, La fuente del Moral o el molino de los Endrinales. Dichas prensas fueron movidas por agua (Molino de las Talas), pero la mayoría serían movidas por caballerías o a mano, y a partir de los años 1930 serán movidas por motores a vapor, electricidad y gasoil.

${ }^{5}$ Véase para el funcionamiento de este tipo de prensas, D. Pequeño y Muñoz Repiso. «Nociones...», pág. 207-215. 


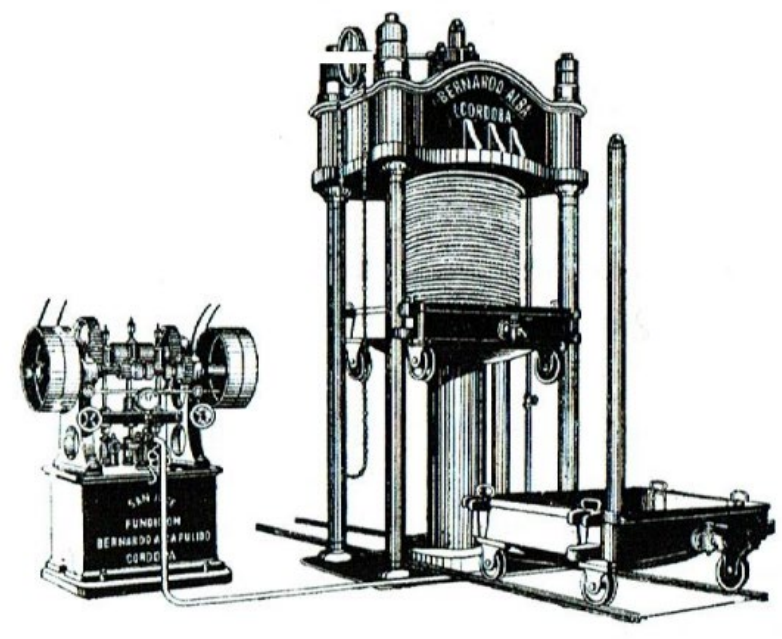

Figura 5. Prensa hidráulica con vagonetas y vía rail (Fuente: Moreno y López, 2017, p. 109).

\section{LOS MOLINOS Y FÁBRICAS DE ACEITE EN MONTEFRÍO}

Para abordar el estudio de los molinos conocidos en el término de Montefrío lo vamos a dividir en dos grupos, aquellos que se sitúan en el término municipal y los localizados en el casco urbano o en las inmediaciones del mismo. Para su estudio hemos contado con varias fuentes de información: de archivo, las conservadas en el Ayuntamiento de Montefrío relacionada con el padrón de vecinos y el padrón de riqueza, así como la información obtenida en el registro de la propiedad de Montefrío. Unido a la información oral ${ }^{6}$, fotografías antiguas y la fotografía área que posibilita ver las estructuras de los antiguos molinos.

A raíz del estudio realizado de documentación de archivo hemos podido comprobar cómo la fisonomía de los molinos montefrieños fue similar en cuanto a su arquitectura e ingeniería a otros muchos tanto en la provincia de Granada como en el resto de Andalucía. Estos irán evolucionando según los cambios tecnológicos y el mercado, pero en resumen el molino debía de tener una serie de instalaciones que vienen a coincidir con las que señala Birriel (2015):

1. El edificio o construcción donde se enclava el ingenio y la maquinaria, así como diversas dependencias: almacenes, corrales, trojes, pozuelos, pilares, pajares...

${ }^{6}$ En la obtención de dicha información se procedió a entrevistas con antiguos propietarios y trabajadores de molinos y fábricas. 
2. El molino, compuesto por el alfarje y los rulos sobre el empiedro, cuyo mecanismo es de rotación, movido a sangre o agua, con el fin de dar movimiento al mecanismo de trituración propiamente dicho. El sistema se compone de dos muelas, una fija o solera y otra móvil que sería cilíndrica o troncocónica.

3. La prensa, una vez que la aceituna ha sido molida era prensada en la almazara. Este mecanismo en Montefrío en origen sería la prensa de viga, que después irá evolucionando a las de torre, husillo y las hidráulicas, hasta ser abandonadas por el sistema continuo de centrifugado.

4. Dentro del sistema destaca el horno y la caldera, para la extracción del aceite con agua hirviendo, para el escaldado de los capachos siendo fundamental en estas instalaciones.

5. Una parte fundamental en la estructura de los molinos o almazaras serían los canales y pilones o alpechineras, necesarias para la conducción y decantación del aceite, y la posterior evacuación de alpechines, borras o turbios.

6. Finalmente destacarían las bodegas, realizadas en obra hidráulica, con un circuito de tinajas, etc.

A todo lo anterior, habría que unir los aperos utilizados por los maestros molineros y los mozos (cagarraches) que en ellos trabajan (Birriel, 2015, p. 45).

La construcción de los molinos aceiteros de Montefrío solía estar realizada en mampostería enfoscada y con sus paredes enjalbegadas, cubiertas por cal, yeso o tierra blanca, como vemos en los restos conservados de diversos molinos, los algorines de la Tranca, Casería de la Jimena o la Fuente del Moral, por ejemplo.

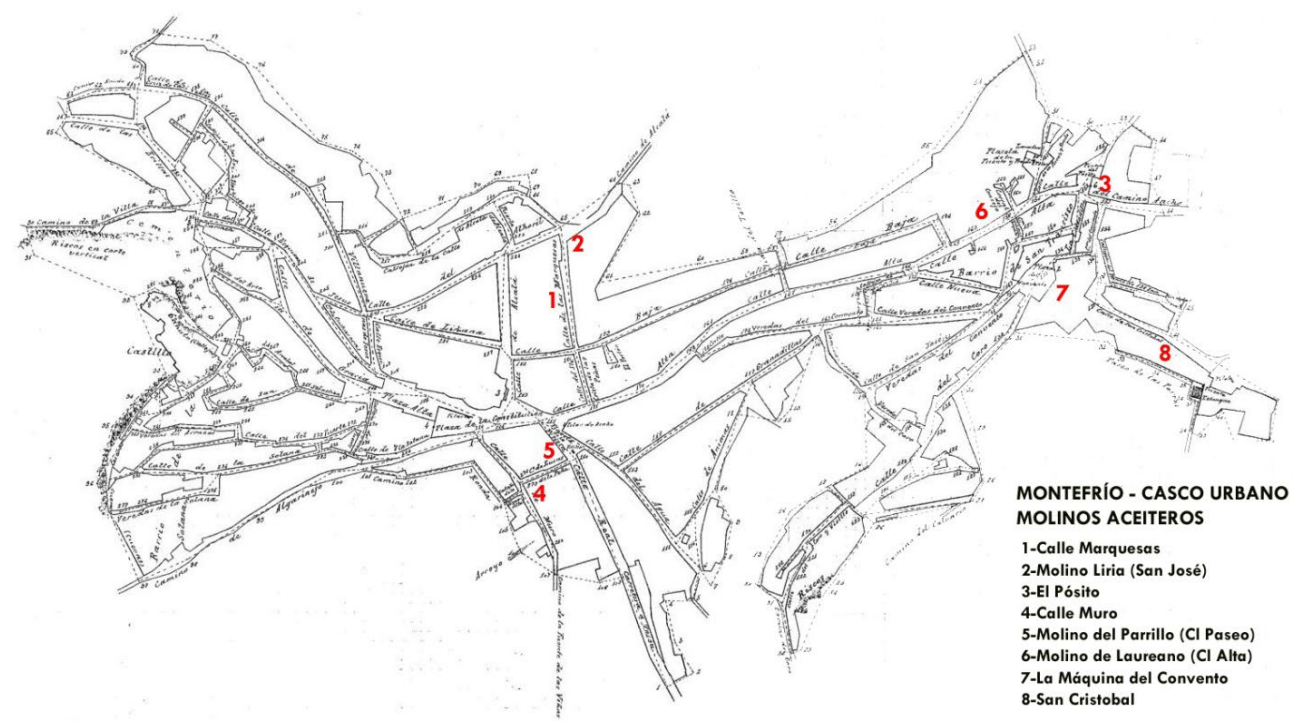

Figura 6. Ubicación de los molinos del casco urbano de Montefrío (Elaboración Felipe Jiménez, a partir de Mapa Topográfico I. G. M. E. Año 1894). 
A partir de finales de los años 70 del pasado siglo los nuevos molinos y fábricas de aceitunas se adaptarán a los nuevos tiempos cambiarán sus patios y los adaptarán para la recepción de la aceituna, con limpiadoras, pesadoras y lavadoras en el lugar que muchas veces ocuparon llos empiedros y caballerizas en el patio y los trojes. El lugar que ocupó la prensa será reutilizado para poner la nueva maquinaria de centrifugado continuo.

A continuación, describiremos los molinos y almazaras documentadas en Montefrío desde mediados del siglo XVIII hasta nuestros días.

\subsection{Molinos en calle Las Marquesas}

En la calle de las Marquesas existieron dos molinos uno en la parte alta de la calle y otro en la parte baja de la misma, conocida como Zanjón. Este topónimo nos indica que dicha zona sería un cauce o zanja grande y profunda por la que correría el agua, procedente de la fuente de las Pilillas y de la calle Agua (Pedregosa, 2012, p. 91), situadas al $S$ de dicha calle. El agua encauzada sería utilizada en ambos ingenios tanto para los estanques como para el funcionamiento de ambos molinos aceiteros.

El molino de las Marquesas se ubicaba en la esquina con la calle Baja, en el patio que ocupaba una vivienda situada en dicha calle. Alrededor del patio se encontraban una serie de dependencias como el cuarto de molienda, fogón, local de la prensa, cuarto de las tinajas, y un pajar alto. La aceituna era recogida en 25 trojes, además contaba con un estanque. El patio superaba una extensión de $202 \mathrm{~m}^{2}$. El molino fue construido por Juan José Pérez Arco sobre el año 1871. Posteriormente fue adquirido en 1904 por Pedro Pérez Ávila y su mujer Dolores Alcaide García. En 1910 será vendido a Cesáreo García Rodríguez, pasando posteriormente a sus hijos, y en 1925 era propiedad de Felipe García Gómez. A partir de estas fechas el inmueble pasó a diversas manos dejando de funcionar como tal, por los datos que se conservan en el Ayuntamiento de Montefrío, en vísperas de la guerra civil. El molino aparece mencionado como un molino de husillo en documentos de archivo del Ayuntamiento de Montefrío, ya en 1883 y posteriormente en los padrones de riqueza de 1906-1909 a nombre de Pedro Pérez Ávila. En los posteriores a 1929 figura como titular Felipe García Gómez, dejando de aparecer en la documentación relativa a los molinos aceiteros a partir del año $1935^{8}$.

Al final de la década de los 40 del pasado siglo y hasta la primera mitad de la de los 70 , en el patio de este molino hubo lo que también se denominaba "posada», para caballerías, especialmente mulos y burros, que es lo que más abundaba, y que

7 Nota simple informativa de la Finca de Montefrío 2099, número 18009000089199 Registro de la Propiedad de Montefrío 1 junio de 2018.

8 Archivo Municipal de Montefrío (AMM). Sala A. Estantería 6.5.4 Impuestos Estatales Padrón de riqueza territorial. Caja 1, años 1884-1936 1906-1909, 1929-1935. 


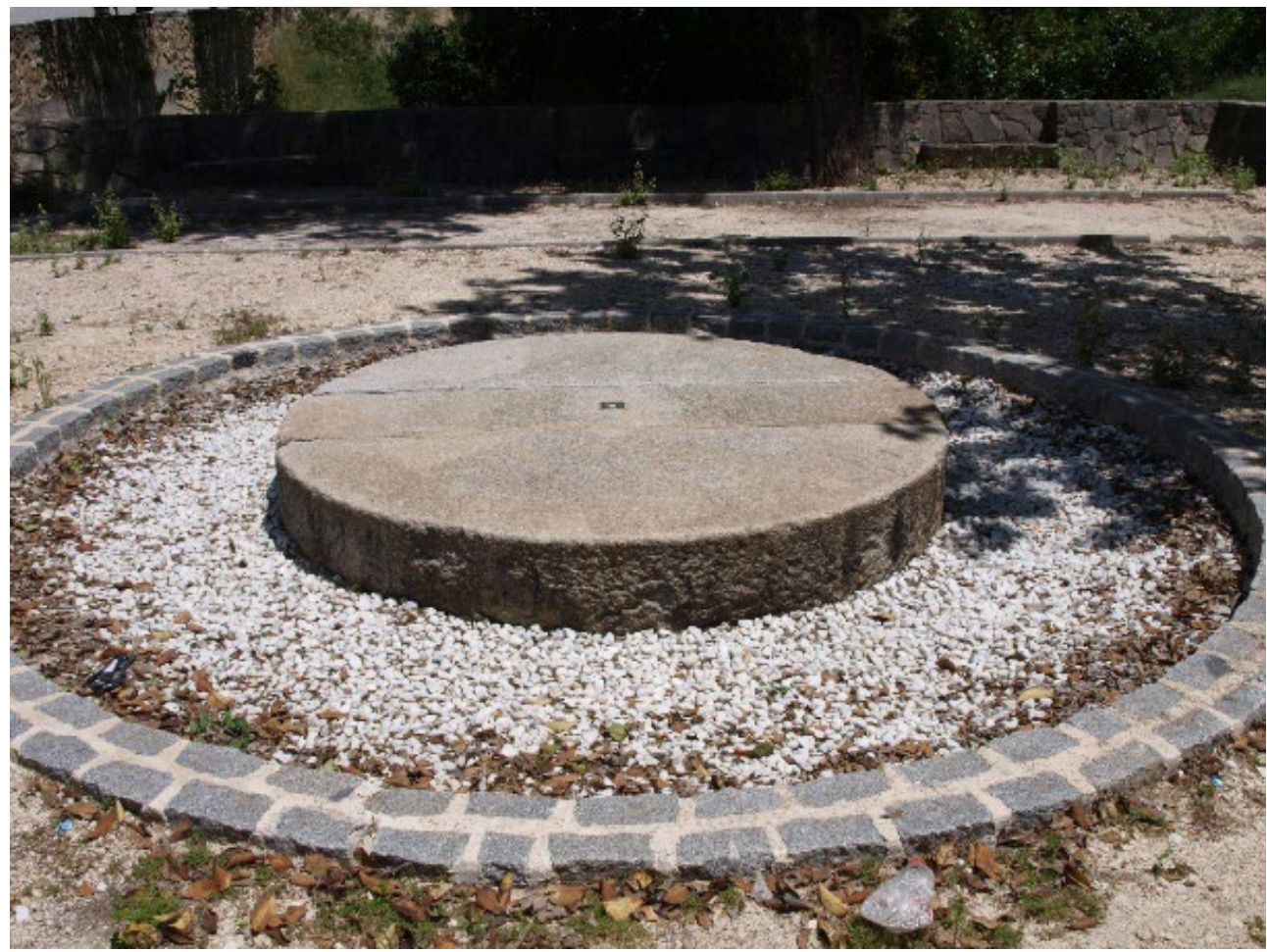

Figura 7. Piedra solera o empiedro de granito que formaba parte del alfarje de un molino aceitero, ubicada en el Parque de Fuente Molina procedente del molino «Liria».

también incluía la posibilidad de herrarlas, ya que en una parte de lo que serían las instalaciones del molino, en el interior de dicho patio, tenía su taller un maestro herrador, propietario de dichas instalaciones y de una casa anexa. Era Bartolomé Rodríguez Arco, conocido como "Bartolo el herrador (jerraor)», cuyos herederos siguen siendo los propietarios de dicha finca.

El otro molino del Zanjón, conocido como "Molino de Liria» y con el nombre comercial de Fábrica de Aceites San José, se ubicó en los terrenos que actualmente ocupa la Residencia de mayores San Sebastián (Figura 7). Su origen se remonta al último cuarto del siglo XIX, estando documentado ya en 1878. Posteriormente es mencionado en los padrones de riqueza entre 1906-1909 ${ }^{\circ}$. El molino constaba de una prensa hidráulica movida por caballerías y fue propiedad de la familia GarcíaValdecasas, siendo en 1933 su dueño Rafael García Valdecasas y García Valdecasas $^{10}$. También aparece en un inventario que realizó el Ayuntamiento de Montefrío

9 AMM. 5.4 Impuestos Estatales Padrón de riqueza años 1906,1907,1908,1909.

10 Nota simple informativa de la Finca de Montefrío 21958, número 180090001456635 Registro de la Propiedad de Montefrío 31 agosto de 2016. 
en 1940 (ver Figura 31), bajo la denominación de molino aceitero y la titularidad del mismo, pasando en 1942 a sus descendientes García Valdecasas y Guerrero. A partir de 1952 fue adquirido por don Diego López Moreno (a Liria), siendo gestionado por su hijo don Antonio López Novo de 1958 a 1969, año en que parece que dejó de funcionar.

Como mencionamos anteriormente, es conocido desde el 12 de febrero 1878 como propiedad de don Juan García Vozmediano. El molino era una fábrica de aceites con una extensión de más de $4227 \mathrm{~m}^{2}$, compuesta de patio con algunos atrojes o trojes, alzándose en su parte central el edificio destinado a la fábrica, compuesto de dos cuerpos. El primero tenía una superficie de $84 \mathrm{~m}^{2}$ y contenía toda la maquinaria correspondiente, una prensa hidráulica movida por caballerías y en el segundo de $42 \mathrm{~m}^{2}$, se localizaba una tinajera. Existían varias estancias más, una de $30 \mathrm{~m}^{2}$, que también contenía otra tinajera, una cuadra para la caballería con $15 \mathrm{~m}^{2}$, así como "otra pequeña estancia de $9 \mathrm{~m}^{2}$, que tiene tinajas en planta baja y una habitación en alto". Encima de los cuerpos que contienen tinajeras existían unos entabacados dedicados a pajares. En el interior del patio había un "estanque que se surte de agua con los derrames de dos pilares públicos y que está destinado a las necesidades de la fábrica»; también había un pozo destinado al mismo servicio ${ }^{11}$.

Dicho molino fue conocido como el de "Liria» y en el trabajaron distintos montefrieños, Juan Rafael «Petaco», Juan «Zurrumbela», Juanillo "Casino», Marcelino, Pepe «Raspa», Rafalillo Chica, Tobas «Salas» (Guzmán, 2010).

\subsection{Fábrica de aceite conocida como San Mauricio en el Pósito}

Los Pósitos (también denominados con el nombre de alhorí) eran una antigua institución que almacenaba cereal para prestarlo, especialmente a los agricultores para que tuviesen semilla para la siembra, y que se recuperaba una vez recogida la cosecha, incrementando la cantidad prestada en la parte que correspondía a los intereses establecidos que por lo general eran módicos. En Montefrío se documenta la existencia de otro edificio destinado a Pósito construido en 1775, por tanto, con anterioridad al que nos ocupa cuya construcción sería en 1795, ambos costeados con caudales propios.

La construcción del nuevo se debe a la necesidad de un almacén público de grano de mayores dimensiones, como consecuencia del aumento de población de la villa. El maestro de albañilería granadino Diego Ramírez de Avellano es el encargado para la selección del solar donde construir la nueva panera (Gil et al., 1991, p. 273). Se empieza a construir en 1780 en el lugar de Fuente de íllora tras la compra de unas casas, ya que presenta unas condiciones favorables tanto de acceso como

11 Ibidem. 
de comunicación en un lugar de expansión del municipio a lo largo del siglo XVIII (Pedregosa, 2012, p. 100).

El diseño de la obra fue realizado por Ventura Rodríguez y Vicente Bois, aunque el arquitecto que acabó realizando la obra fue Francisco de Aguado.

El edificio es de planta rectangular y su interior diáfano con tres naves separadas entre sí por dos hileras de cinco pilares cuadrados que soportaban la armadura de madera de la cubierta a tres aguas con teja. Delante de las naves se ubicaba un primer sector paralelo a la fachada con una habitación a un lado y en el otro, una escalera que conducía a una entreplanta abierta al vacío de las naves. La fachada presenta una composición simétrica, con el acceso en el centro y dos ventanas laterales, un frontón triangular sobre imposta que recorre todo el alzado principal. En el tímpano del frontón se sitúan un escudo borbónico, una ventana y una placa con la inscripción conmemorativa de su construcción (Gil et al., 1991, p. 275).

Este edificio fue por tanto una obra construida a finales del siglo XVIII (17801795), para destinarlo a Pósito con el consiguiente almacenamiento del cereal producido en los campos de Montefrío durante todo el siglo XIX y principios del XX, pero que, una vez monetarizados los caudales en grano de los mismos, dejó de tener la utilidad pública a la que se había destinado y por tanto privatizado mediante la venta del mismo, que pasó a manos de particulares. El avance de la producción del olivar llevó a los nuevos propietarios a destinar el edificio a fábrica de aceite ya en la década de 1920.

A partir de 1928, la fábrica que ocupaba el edificio que antaño se había dedicado a Pósito Municipal y que desde entonces se ha conocido a nivel popular como "El Pósito» contaba con una prensa hidráulica a vapor, siendo su encargado Juan Rodríguez Pérez. En 1938 la prensa pasaría a ser movida por electricidad, siendo los encargados de este molino diferentes; en 1938 Francisco Agea Navarrete, en 1939 José Guerrero Coca, 1940 Francisco Cano Nieto. El Pósito era mencionado en 1940 como fábrica de aceite supervisada por José Guerreo Coca en el listado que realizó el Ayuntamiento de Montefrío en dicho año (ver Figura 31). Dicha fábrica parece que funcionó hasta el año 1944, año a partir del que se abandona para este uso.

Este molino contaba con un despacho o sucursal para la venta de aceite en la calle Lucas Peña, y aparecía anunciado en el periódico Patria de Granada a mediados de los años 1950, al igual que otros de Montefrío.

\subsection{Fábrica de aceite en calle Muro, Lucas Peña}

Son pocas las referencias que tenemos acerca de este molino, que no conserva actualmente ningún elemento industrial. En la documentación de archivo sabemos que fue propiedad de Mauricio García Valdecasas en 1883. Aparece recogido 
posteriormente en los padrones de riqueza de 1906-1909, mencionado como molino de husillo propiedad de Alfonso M. García Valdecasas. En 1928 y hasta 1933 aparece recogido como un molino del mismo tipo y propietario ${ }^{12}$. También consta información del mismo, en un listado fechado el 15 de febrero de 1940 (ver Figura 31), que recoge los molinos aceiteros de Montefrío, como molino de aceite propiedad de D. Rafael Alba García Valdecasas.

A partir de 1958, aparece de nuevo dicho molino siendo su titular Pedro Arco Pérez hasta 1964. En adelante, desde 1967 a 1969, año en que se abandona, el titular de la actividad fue Luis Fuentes Aguilera ${ }^{13}$.

Posteriormente pasó a manos de los hermanos Pedro y Antonio Muñoz Pérez en cuyo solar edificarían algunos pisos y su taller de herrería, posteriormente carpintería metálica que ha permanecido en uso hasta 1997.

\subsection{Molino aceitero en callejón Lucas Peña-Paseo}

Este molino estaría en funcionamiento antes de 1883 , ya que aparece mencionado en documentación de archivo del Ayuntamiento de Montefrío; en ese año pertenecía a D. Alfonso García Valdecasas y Cubero. Es mencionado en los padrones de riqueza de 1906-1909, donde aparece recogido como un molino de husillo, siendo su titular él mismo ${ }^{14}$. A su muerte lo heredaran sus hijos, siendo la titularidad del mismo entre 1928 y 1938 ejercida por D. Juan M. a García Valdecasas Moreno, período en el que este molino fue adaptado a los tiempos con una prensa hidráulica a vapor ${ }^{15}$. Desde 1939 su titular sería Rafael Alba García Valdecasas, figurando en el listado que realizó el Ayuntamiento de Montefrío en 1940 (Figura 31), denominado este ingenio como molino aceitero. A partir de 1958 será propiedad de su hija, doña Dolores Alba Guerrero, y su esposo don José Mercado Ariza, hasta el año 1969 en que dejaría de funcionar dicho molino.

El molino se ubicaba en la esquina del callejón del Maestro Peña (Lucas Peña) con la antigua calle General Franco n.ㅇ 8, actualmente calle Paseo. El edificio tenía un portón al citado callejón de acceso a los corrales y tenía una superficie total de unos $645 \mathrm{~m}^{2}$. Este molino, fábrica de aceite, contaba con todos los artefactos útiles para la industria, como pozuelos, tinajas, cuadras, patio con sus trojes para depositar la aceituna, etc. Fue conocido como el molino del "Parrillo», por ser este el

${ }^{12}$ AMM. 5.4 Impuestos Estatales Padrón de riqueza territorial. Caja 1, años 1906-109, 19281933.

${ }^{13}$ AMM. 5.4 Impuestos Estatales. 5 cajas (Años 1945-1991). Legajos años 1958-1964. 19671969.

${ }^{14}$ AMM. 5.4 Impuestos Estatales Padrón de riqueza territorial. Caja 1, años 1906-1909.

15 Nota simple informativa de la Finca de Montefrío 6837, número 18009000229366, Registro de la Propiedad de Montefrío 10 enero de 2017. 

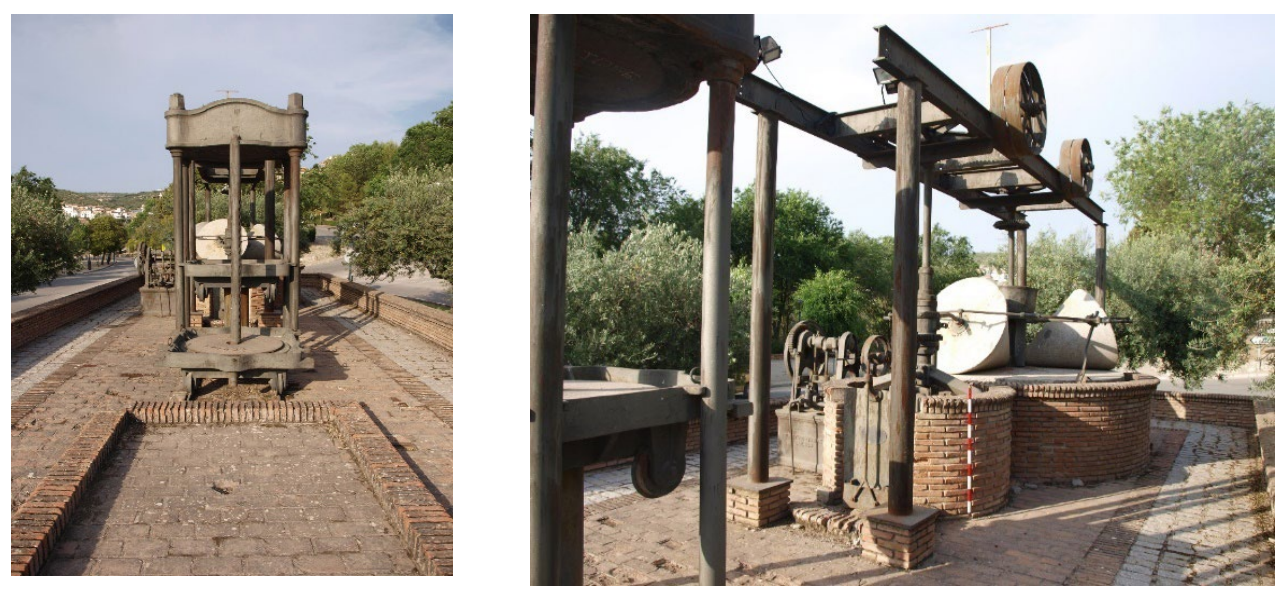

Figura 8-9. Molino y prensa hidráulica de la fábrica de aceite que existió en El Paseo esquina Juan de Carrión. (Monumento al Olivo). Se observan la prensa, los rulos y el alfarje, vagoneta, así como los mecanismos de transmisión...

alias de la familia propietaria en último extremo, y en él y sus máquinas trabajaron distintos montefrieños durante la década de los 50; Bernardo, «Falete», Juan "Calvarios», "Los Cocas»... (Guzmán, 2010).

En la actualidad el solar se encuentra expedito y, por tanto, sin construcción alguna.

\subsection{Molino aceitero en Calle Alta, 93 (molino de Laureano o Ramírez)}

Los datos con los que contamos para este molino son similares al resto. Este estaría en funcionamiento como mínimo desde 1866, año en el que aparece recogido en el catastro. Su propietario era D. Francisco Antonio Fuensalida y Peña que compró a doña Ana García Valdecasas y Gordo la mitad del mismo y que pasó a doña M. a Josefa de Vega y García Valdecasas en 1866. Por estas fechas el molino también perteneció, la otra mitad del mismo, a D. José Guerrero García Valdecasas, que lo heredó de su padre D. José Guerrero Narváez y de su tío Alfonso, dejándolo en herencia a su hija doña Carlota Guerrero Mira en 1896. Pocos años después, tras la muerte de María Josefa Vega García Valdecasas, la mitad del molino pasa a su hija Dolores Fuensalida Vega, casada con Andrés Fernández de Cañete, que tras el fallecimiento de su mujer pasa a su hijo Francisco Fernández de Cañete Fuensalida en 1902. Posteriormente y bajo la titularidad de este, aparece recogido en los padrones de riqueza de 1906 a 1909, con una prensa de viga. A partir de 1928 y como mínimo hasta 1935 el molino contaba con una prensa hidráulica accionada a mano y sustituida posteriormente por caballerías, aunque seguía manteniendo la misma estructura y distribución previa ${ }^{16}$.

16 AMM. 5.4 Impuestos Estatales Padrón de riqueza territorial. Caja 1, años 1906-1909. 
Su titular era Francisco Fernández de Cañete Guerrero. En el listado del Ayuntamiento de 1940 (ver Figura 31) era denominado como molino aceitero, siendo sus propietarios los herederos de Francisco Fernández de Cañete Fuensalida. El molino estuvo en funcionamiento hasta 1945, cuando causó baja, siendo su propietario José Fernández de Cañete. Poco después, en 1947, el molino fue comprado por Laureano Ramírez Coca y su mujer, manteniéndolo en funcionamiento hasta $1969^{17}$.

Este molino fue conocido también como el molino de «Laureano» o de «Ramírez» y en él trabajaron igualmente algunos montefrieños conocidos como «Fasia» o «El Trompo» (Guzmán, 2010).

El molino de aceite constaba de tres cuerpos con dos vigas, rulo, piedra, pilonera, hornillo, sala, cámaras, cuadra, pajar, alpechinera o jamilera, patios y trojes. Tenía de fachada $16 \mathrm{~m}$ y $332 \mathrm{~m}^{2}$ de edificio. Los patios tenían una superficie de $487 \mathrm{~m}^{218}$. En el solar que ocupaba, en la actualidad hay dos bloques de pisos.

3.6. Fábrica de aceite en la Placeta del Convento, antiguo convento hospicio de la orden San Francisco dedicados a la Observancia

El convento de la iglesia de San Antonio estaba formado hasta mediados del siglo XIX por varias dependencias articuladas en un conjunto unitario, estas eran las típicas de cualquier monasterio o casa de religión; la iglesia de una sola nave sin transepto acusado y ábside parecido a la del convento de San Francisco el Real, la casa-residencia de los frailes con su claustro, refectorio, celdas o dormitorios, noviciado, el hospicio, la sala capitular, sala de profundis o sala intima de velatorio y rezos, cocinas, almacenes, además de una extensa huerta aneja. Todas las estancias del convento, así como sus muebles serían donaciones de los ciudadanos que habitaban Montefrío (Pedregosa y Martínez, 2007).

Tras la ley de 19 de febrero de 1836 hasta su suspensión por el gobierno moderado el 8 de agosto de 1844, tendría lugar la política desamortizadora emprendida por Mendizábal. Así, al recibir los inventarios de bienes de algún convento y dada la lentitud con que se entregaba, la Junta Provincial acostumbraba a sacar a subasta todos o la mayoría de los bienes que poseían en los pueblos que se tenían relaciones (Gómez, 1983). Sabemos por la consulta del Archivo Diocesano de la Curia de Granada, que se desamortizaron una serie de obras del Convento de San Antonio, sobre todo alhajas de oro y plata, haciendo el inventario Francisco López Rojas el 7 de febrero de 1838 (Pedregosa y Martínez, 2007, p. 261).

\section{8-1935.}

17 Nota simple informativa de la Finca de Montefrío 768, número 18009000244758, Registro de la Propiedad de Montefrío, 20 de diciembre de 2017.

18 Ibidem. 
Las desamortizaciones que tuvieron lugar a lo largo del siglo XIX, y particularmente la de Mendizábal y Madoz fueron las más importantes. Estas supusieron la marcha de los monjes franciscanos de Montefrío y el paso de la iglesia al clero secular. Tras la venta del edificio, este sufrió modificaciones para adaptarse a las nuevas necesidades, casa de vecinos, Cuartel de la Guardia Civil (1879-1884) (Jiménez, 2014), tiendas, posada, horno de pan y molino de aceite, lo que provocó la creación de estancias nuevas, derribos o fabricación de muros medianeros que definirían nuevos espacios en el antiguo convento, según las necesidades y los nuevos usos para los que fue destinado.

En la planta de este edificio se hallaba instalada una fábrica de pan y distintas dependencias, la zona alta, en torno a la galería que da al patio, se destinó a vivienda, teniendo esta otra entrada independiente desde la Placeta del Convento, mediante unas escaleras que surgían en un portal anexo a la iglesia que da a esta placeta. En la espalada del edificio se ubicó un antiguo molino aceitero.

El lugar fue conocido como la "Máquina» durante la segunda mitad del siglo $\mathrm{XX}$, ocupando los restos del antiguo convento franciscano ya desamortizado, construido en el siglo XVI. El convento tenía patios y huertas a sus espaldas, obedeciendo probablemente esta denominación a su uso mixto como residencia conventual y casa de labor, con molinos, almazara, bodegas y graneros de los productos que beneficiaban al convento franciscano (Gil et al., 1991, p. 275).

A partir de la década de 1880, la antigua "Casa que fue Convento» se aprovechó para la construcción de un molino aceitero en parte de la estructura del mismo, en torno a las zonas de patios y la fachada posterior. Los patios eran conocidos como el de las "colmenas», con trojes para el servicio del Molino Aceitero, otro patio lindante con la Iglesia y la Sacristía, llamado de los «Cameros», y otro muy pequeño en el que se ubicaron tres depósitos de la jámila del molino. En la planta baja del edificio se encontraba el molino de aceite, que tenía una prensa hidráulica de doble presión; dos rulos en un solo empiedro, dos calderas, un depósito de piedra para las masas, varios pilones y tinajas para aceite y otros utensilios necesarios para el artefacto. El molino pertenecía a don Antonio Amor y Jurado, que probablemente adquirió el edificio tras la desamortización, y lo vendió a don José María Morales y Jiménez, que era cura en 1879. Poco después fue adquirido por una sociedad creada por Marcelino de Torres y Rosales y Antonio Martin de Rosales Gómez, para la instalación y explotación de una fábrica de harinas y aceites, siendo conocida la sociedad «Rosales, Torres y Compañía», que estaría en funcionamiento en el año 1887.

La fábrica de harinas por su parte constaba de dos calderas de vapor con sus correspondientes transmisiones, cuatro piedras, una amasadora, dos hornos, limpiadora, ascensores, clasificador de harinas y dos estanques. Esta se ubicaba en el lateral derecho del edificio entrando por la calle que sube al Calvario.

Pocos años después la sociedad se disolvió, concretamente en 1897, y sus propietarios llegan a vender en 1911 las instalaciones a Francisco Rico Pérez, 
perteneciendo dicho molino desde entonces a la familia Rico Rico hasta 1970. En la década de 1960 parte del edificio e instalaciones de molino de pan fueron adquirida por la familia Serrano, siendo a partir de 1970 la zona del antiguo molino aceitero propiedad de Antonio Cano, que la convirtió en su vivienda.

En documentación de archivo procedente del Ayuntamiento de Montefrío, concretamente en los listados de contribución industrial, este molino figura en el año 1928, con una prensa hidráulica movida a vapor, siendo su dueño José Antonio Rico Pérez. A partir de 1940 (ver Figura 31), aparece mencionado en el listado que hace el Ayuntamiento sobre los molinos y fábricas de aceite, y lo denomina fábrica de aceite, siendo su titular D. Nicolás Rico Rico.

En el suplemento al núm. 6108 del periódico Patria, correspondiente al día 30 de marzo de 1955, dedicado a la producción de aceituna y molinos aceiteros de la provincia de Granada, figura un artículo sobre esta fábrica según el cual era conocida como Fábrica de Aceite "San Antonio» y ratifica que su propietario era el Sr. Rico Rico. En este se describen sus elementos esenciales que eran: empiedro de dos rulos, termofiltro de "Palacín» y una prensa hidráulica de treinta cm de pistón. La fuerza motriz la proporcionaba la «red eléctrica y el gas-oil» con sendos motores de «diecinueve y quince caballos respectivamente». Su capacidad de molturación ascendía a doce mil kg de aceituna diarios y tenía capacidad para almacenar cincuenta mil kg de aceite. Según parece, dejó de funcionar en 1968.

En este molino conocido como "La Máquina» trabajaron entre otros a lo largo de los años 1940-1950 "Los Frasquillos», José "Sonete», Juanillo «El Sacristán», «Palino» y su hermano, «Los Potras», «El Rubio Torres» (Guzmán, 2010).
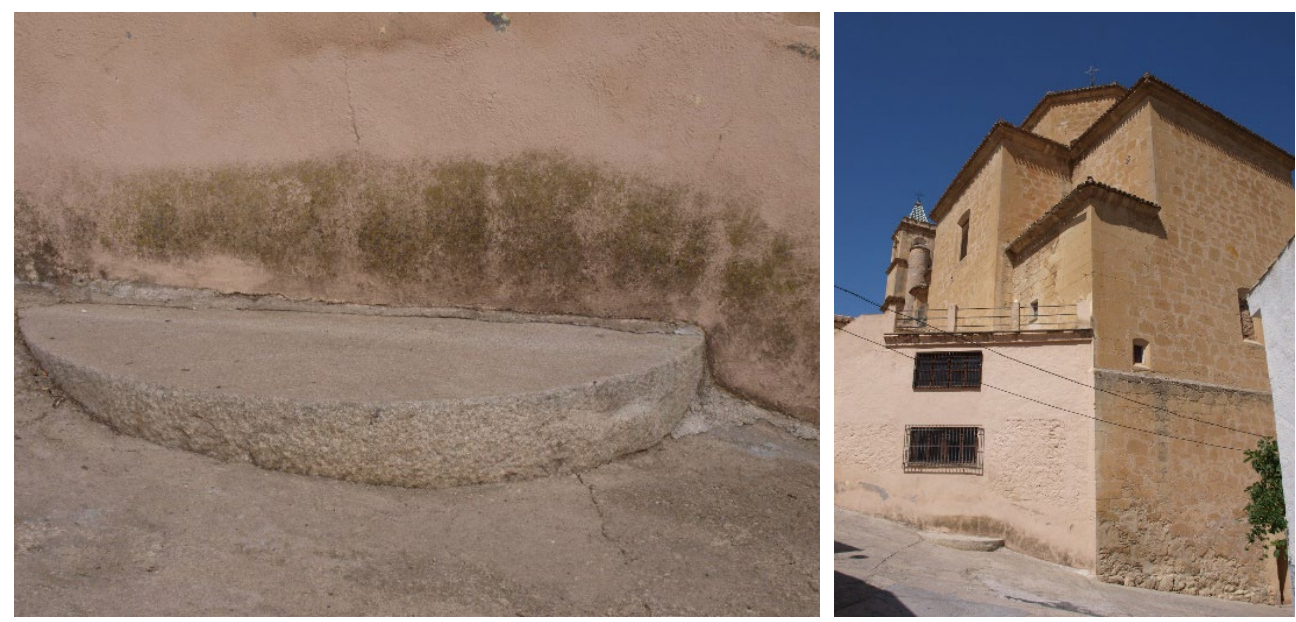

Figura 10-11. Piedra de molino bajo la construcción de la sacristía de la iglesia de San Antonio. 
Gracias a una intervención arqueológica vinculada a la rehabilitación del antiguo Convento realizada durante el año 2006, pudimos comprobar parte de las instalaciones y dependencias que ocupó dicho edificio, así como las modificaciones sufridas por el paso del tiempo y el cambio de uso tras el proceso desamortizador. Durante dicho estudio comprobamos en qué parte se habían ubicado las industrias molineras, sobre todo la relacionada con el aceite; tras el picado de paramentos y levantamiento de suelos pudimos comprobar poleas, rebajes en los muros, la construcción de pozos, la apertura o cierre de vanos en función de la necesidad, sobre todo en la planta baja, de lo que fue la antigua vivienda de Antonio Cano. Se construyeron nuevos vanos más grandes, se rebajaron los grosores de los muros para colocar los elementos de molienda, tinajas, además sistemas de poleas y correas para los engranajes de la maquinaria del molino, así como chimeneas y hornos vinculados a la fábrica de aceite que daban al exterior del edificio, en la zona de huertas. También se documentaron algunos pozos negros realizados en el subsuelo para su uso durante la ocupación del claustro como fábrica de aceite. En definitiva, se realizaron obras tras la desamortización del edificio para su adaptación a fábrica de aceite, como prueban los resultados arqueológicos obtenidos. En las inmediaciones de la iglesia en lo que actualmente es la sacristía de la Iglesia de San Antonio, se aprecia parte de una de las piedras de molienda que formó parte del empiedro del antiguo molino aceitero perteneciente a Nicolás Rico Rico (Pedregosa y Martínez, 2007; Pedregosa, 2010; Pedregosa, 2018).

\subsection{El molino de San Cristóbal}

Uno de los dos molinos que figuran en el Catastro de Ensenada (1752) y por tanto de los primeros de los que se tienen referencias, era propiedad de doña María Ramírez, una rica hacendada y labradora que además tenía un molino de pan en la rivera de Mairena, un horno de pan en la calle Santo Cristo, tres casas más en el casco urbano, cinco en el campo y fincas por varios rincones del término municipal que sumaban más de 500 fanegas de tierra, de las que 5 eran de olivar de regadío y 10 de olivar de secano. También tenía una viña de 4 aranzadas de primera calidad en Los Majuelos.

El molino tenía 26 varas de fachada por 20 de fondo, se ubicaba en el Barrio de la Fuente de íllora en el sitio de San Cristóbal, según figura textualmente en dicho catastro. Tenía una bodega con "seis tinajas para azeite de cabida cada una de cien arrobas y diez [pozuelos] con cabida de ciento y cinquenta arrobas con sus trojes y demás pertrechos correspondientes». Estaba integrado en un huerto murado de dos celemines en el que había parrales e higueras. Este se ubicaba en uno de los ruedos de la villa, concretamente en la zona de las huertas de la Capellanía pertenecientes a la orden de los Franciscanos asentados en Montefrío, formando parte de una Tercia de las instalaciones que tenía el antiguo convento franciscano, lugar que ocupa actualmente parte de la casa e instalaciones del molino de San Cristóbal. 


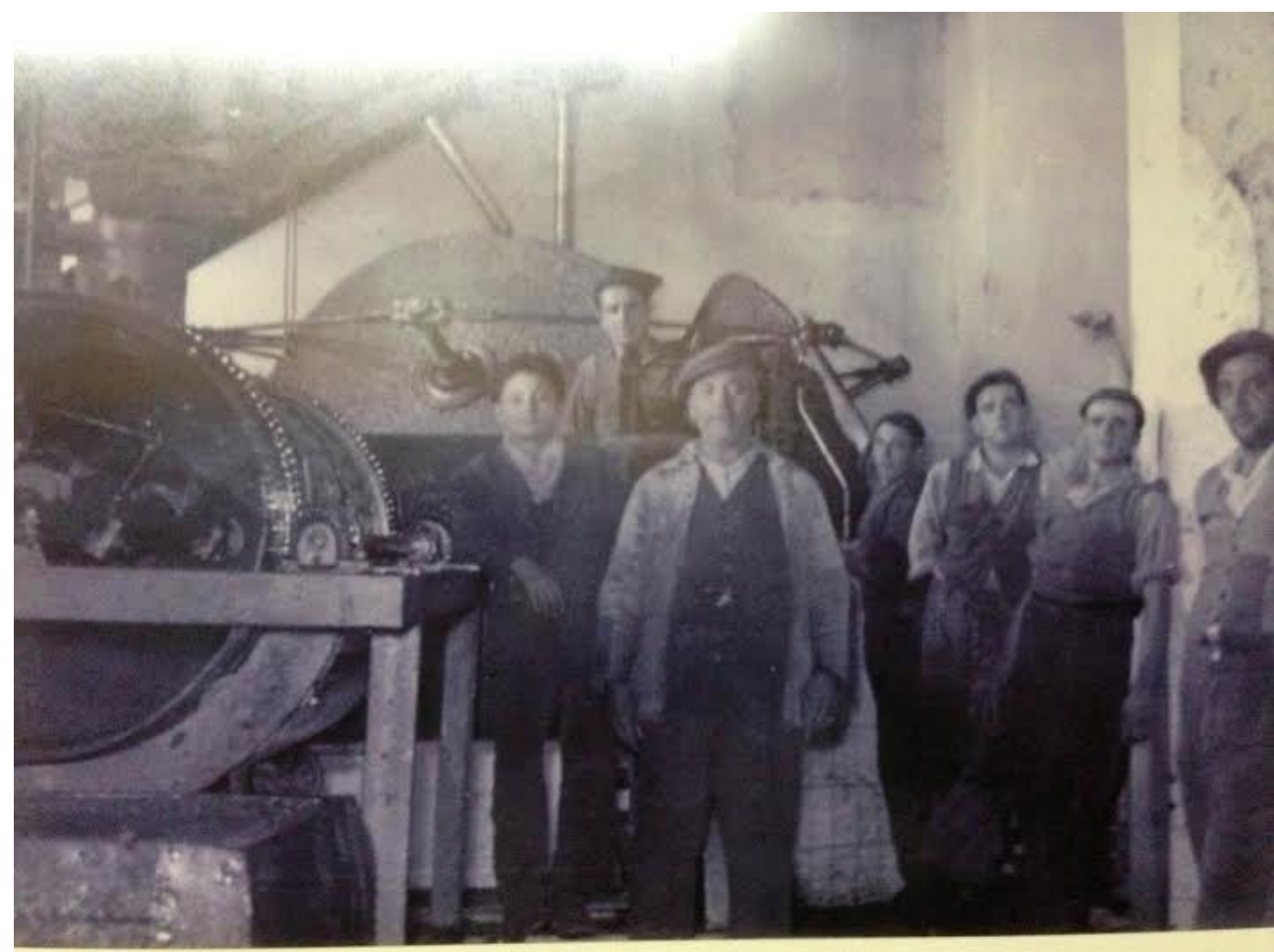

Figura 12. Antigua Fábrica de Aceites San Cristóbal instalaciones del molino (Fuente: Juan Carlos García-Valdecasas Guzmán).

Desde 1896 conocemos que su propietario fue don Juan Guerrero Centeno, que heredó dicho molino de su padre don Antonio Guerrero Narváez, y que tras su muerte se adjudicó a doña Enriqueta Ochen Bouiguez. Poco después sería adquirido por don Francisco Guzmán Vega y don Rafael Torres Rosales en 1897. A partir de 1901 sería propiedad de Rafael Guzmán Vega, pasando posteriormente por herencia a su hijo Rafael Guzmán Pasadas en 1915, perteneciendo el molino a la familia y pasando de padres a hijos; así lo heredará Ana Pérez González, y a continuación sus hijas, siendo adquirido por Ana Guzmán García Valdecasas en 1955.

En la documentación de archivo del Ayuntamiento de Montefrío, es mencionado en los listados de la contribución industrial de 1906 a 1909, con una prensa de viga, siendo propiedad de la familia Rafael Guzmán Vega. A partir de 1928 tendría una prensa hidráulica movida por caballerías, siendo su titular Rafael Guzmán Pasadas hasta el año 1938. Aunque durante el período de la Guerra Civil permaneció cerrado unos años. Desde 1938 será la propietaria Ana Pérez González, siendo así recogido en el listado que realizó el Ayuntamiento de Montefrío en 1940 (ver Figura 31), que lo denomina como molino aceitero. Desde 1958 en adelante será su propietaria Ana Guzmán García-Valdecasas y Rafael García-Valdecasas Ruiz. 
El molino de aceite, que actualmente continúa ubicado en el barrio de San Cristóbal, estaba compuesto de una viga de prensar, con un empiedro de dos rulos pequeños, pilones, bodega, caldera, patio con varios trojes y un huerto cercado que tenía algunos árboles frutales. Durante la época de molienda y elaboración de aceite cogía el agua del pilar de San Cristóbal ${ }^{19}$.

El anteriormente citado suplemento del periódico Patria (de 1955), en el que aparecieron anuncios sobre los distintos molinos, en concreto menciona la propiedad de don Rafael García-Valdecasas Ruíz, y en la entrevista que le hacían al mismo se quejaba de la necesidad de utilizar como fuerza motriz un motor de gas-oil «Deutz» con una potencia de entre 15 y 17 caballos, ya que la compañía eléctrica, entonces la «Eléctrica del Litoral», de forma inexplicable no le suministraba energía. El resumen de sus características era el siguiente: Sistema de molturación tres rulos y sistema de extracción un termo filtro "Palacín» y una prensa hidráulica con pistón de $35 \mathrm{~cm}$ de diámetro. Tenía capacidad para moler hasta doce mil kilos de aceituna en las veinticuatro horas y de almacenaje de quince mil kilos.

De todos los molinos de aceite que existieron en Montefrío es el más antiguo que se conserva, adaptándose al discurrir de los tiempos y los cambios tecnológicos que afectaron a la industria. El molino pasó de tener una prensa de viga en su origen a una prensa movida por la fuerza hidráulica y caballerías, un motor diésel en 1955, así hasta ser hoy una de las fábricas de aceite que siguen activas en Montefrío, con una maquinaria moderna decanter ecológica, denominado popularmente como Molino de San Cristóbal. En este molino trabajaron entre otros "Los Espardillaos», Paco y Pedro Rueda, «El Porreto» y su hijo, «El Teresillo» (Guzmán, 2010).

Ahora cuenta con una limpiadora lavadora para recibir la aceituna en condiciones óptimas que, tras pasar por una de las tres tolvas con capacidad para $80000 \mathrm{~kg}$ cada una, puede procesar $80000 \mathrm{~kg} /$ día, contando para ello desde 2003 con una línea ecológica de dos fases para la extracción del aceite que directamente pasa a la bodega con capacidad de almacenamiento para $400000 \mathrm{~kg}$ en modernos bidones de acero inoxidable.

\subsection{El molino y fábrica de aceite la Cueva, la Tranca y la Enrea}

Es uno de los molinos que menciona el Catastro de Ensenada en 1752, se localiza en el paraje de la Tranca. Su propietario era don Juan Félix de Rabaneda y Soto que además tenía un molino harinero y un batán en la rivera de Mairena (actual arroyo de los Molinos). También era propietario de una tenería en Las Peñas, cuyo nacimiento de agua abastecía al molino de aceite que era conocido como el del

19 Información notarial ofrecida por el actual propietario. Juan Carlos García-Valdecasas Guzmán. Nota simple informativa de la Finca de Montefrío 5424, número 18009000248046, Registro de la Propiedad de Montefrío 10 enero de 2017. 
"Huerto de la Tranca», así como varias casas ( 6 en el casco urbano y 3 en el campo), tres huertos (en la Alcubilla, La Tranca y Mairena), 17 fanegas de olivar (tres de ellas de riego) y otras trescientas fanegas de secano ${ }^{20}$.

El catastro de Ensenada en el vecindario Secular nos menciona este molino de aceite nombrado como el

«Molino del Huerto de la Blanca». Está ynmediato a la población, tiene 15 baras en cuadro. Con sus trojes y patio. Esta yslado en tierras de riego de esta hacienda y según las respuestas generales tiene de utilidad en dicho molino por sus moliendas 550 reales de vellón ${ }^{21}$.

En 1817 es mencionado en el inventario de Garay y su propietario era don Rafael M. - Villacevallos, siendo el mismo que figura en el censo Agrario de 1819. También es mencionado y recogido en otros documentos de archivo del Ayuntamiento de Montefrío en 1883, siendo sus propietarios José M. y Josefa Vega Guerrero. Pocos años después pasó a ser propiedad de doña Dolores Fuensalida Vega, figurando en los padrones de riqueza de 1906 a 1909 a nombre de esta, con la denominación de "La Cueva», como molino con prensa de viga.

El molino de La Cueva pudo en algún momento tener la prensa de torrecilla, ya que en su documentación registral consta que tenía una torrecilla, y tomaba el agua de la Fuente de Las Peñas. El edificio tenía una superficie de $175 \mathrm{~m}^{2}$, el patio rondaba los $218 \mathrm{~m}^{2}$, y estaba situado en el paraje de la Cruz Gorda. El molino constaba de tres cuerpos, en los que se repartían una serie de estancias como patio, trojes, viga, pilonera, hornilla, piedra de molienda, cuadra, pajar, alpechinera y agua en propiedad que tomaba, como se ha dicho de la fuente de las Peñas ${ }^{22}$.

Este molino aparece mencionado en el catálogo de Cortijos, haciendas y lagares de la provincia de Granada, con el nombre de molino de Los Tajos, "se halla arruinado y fue un molino de aceite de viga, de los citados por Madoz» (Tuerices y Zurita, 2003, p. 397).

En la imagen se observan los restos de los distintos algorines, algunos de ellos excavados en la roca, otros en cambio construidos con muros que los separaban, de los que tenemos su huella todavía. Se pueden observar cómo encima de cada uno hay un pequeño hueco en la roca, de forma cuadrada y en el que irían los números en mármol de cada uno de los algorines, aunque desgraciadamente solo queda

20 Catastro de Ensenada. Vecindario Secular, Montefrío-1411, con fecha de 10/5/1753, fol. $108 v, 109 r, 109 v, 109 r, 110 r$.

${ }^{21}$ Catastro de Ensenada, fol. 0109-v.

${ }^{22}$ Nota simple informativa de la Finca de Montefrío 741, número 18009000316882, Registro de la Propiedad de Montefrío 20 de enero de 2015. 

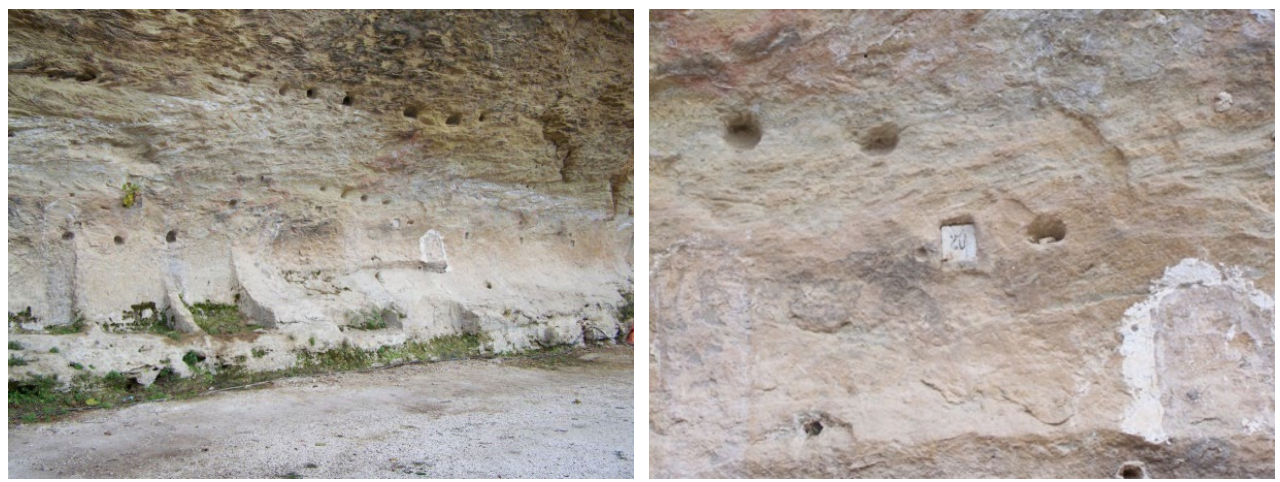

Figura 13-14. Vista de los restos de algorines (trojes) que se conservan del antiguo Molino de la Cueva, y de los distintos hoyos de postes o vigas en la pared de calcarenita bioclástica, característica de la formación geológica de la

Tranca. Detalle de algorín que conserva el número que tenía asignado.

uno. También se aprecian distintas huellas en la roca para colocar vigas de madera, que pudieron cubrir parte de este patio o tener otro fin ya que la zona de la Tranca fue usada como cantera para extraer piedra para diversas construcciones como la iglesia de la Villa a mediados del siglo XVI.

Aunque estemos hablando de un molino, la verdad es que podría considerarse que son dos bien diferenciados, ya que las instalaciones del denominado inicialmente de la Cueva fueron abandonadas para el uso de molino y se construyeron unas totalmente nuevas, en un edificio de nueva planta, separado del otro por el camino de la Tranca o antiguo camino de Granada, también conocido a nivel local como "Camino del Arenal». A partir de 1925 este molino aparece recogido en el plano Topográfico del Instituto geográfico de ese año, y se conocerá como molino de Cañete. Posteriormente el molino pasa a denominarse de la Cruz Gorda, y en 1928 tenía una prensa hidráulica a vapor y su propietario era Rafael Ramírez García. En los años 1932 y 1933 estaba a cargo del molino una sociedad denominada La Unión Agrícola, pasando en 1935 a ser propiedad de Eduardo Pedregosa Trujillo. Poco después, en el listado fechado en 1940 (ver Figura 31), figuraba como fábrica de aceite. Su denominación habría evolucionado a Fabrica de Aceites "La Enreda» por los líos y trapicheos derivados de la molturación de la aceituna, la compra de la misma y la posterior venta de aceite por parte de la citada «asociación». Hasta entonces el sistema utilizado mayoritariamente era el de maquila, por el cual el beneficio de los molinos aceiteros no se obtenía directamente de la comercialización del aceite procedente de aceitunas compradas, sino de lo cobrado por el proceso de extracción del mismo.

Entre 1945 y 1948 figuraba como titular su hijo Pedro Pedregosa Fernández y en 1965 consta una licencia para hacer alguna reforma en la fábrica a nom- 
bre de las hermanas Catalina y María de la Paz Pedregosa Fernández, que eran las propietarias. En 1955, bajo la denominación oficial de «Nuestra Sra. de los Remedios», la explotaba en régimen de arrendamiento don Manuel Morales García. Contaba con un empiedro de tres rulos, una termo batidora y dos prensas hidráulicas con pistón de $35 \mathrm{~cm}$ de diámetro cada una. Empleaba como fuerza motriz la energía eléctrica con un motor de veinte caballos. Podría moler a las veinticuatro horas diez mil kg de aceituna y su capacidad de almacenamiento de aceite era de ciento diez mil kg de aceite ${ }^{23}$. No obstante, entre el año 1958 y el 1968 el titular de la fábrica es Julián Bermúdez Pérez y a partir de 1969 Rafael Pérez Santaella que posiblemente fuera el último en dar uso a estas instalaciones.

Las nuevas instalaciones se asentaron sobre un solar prácticamente rectangular de unos $75 \mathrm{~m}$ de largo por 20 de ancho totalmente cerrado, en su parte ubicada más al sur por una tapia, de la que aún quedan restos, que constituía el patio del este, de unos $50 \mathrm{~m}$ de largo, en el que había un muro central con escaleras al principio del mismo para poder subirse a él y, utilizándolo como muelle, poder ir amontonando la aceituna que había llegado envasada en sacos. El otro extremo del solar cerrado por tres naves de unos ocho metros de ancho cada una, adosadas, paralelas y comunicadas entre sí y con el patio, que albergaban todas las instalaciones necesarias; tinajas, pozuelos decantadores, almacén, etc., así como la ya moderna maquinaria que pronto pasaría a ser movida por energía eléctrica, tanto los rulos para la molturación como las dos prensas hidráulicas. Adosada a estas naves, en el lado opuesto al patio y en sentido transversal a las mismas, es decir, paralela al camino del Arenal, estaba la vivienda destinada al encargado del molino.

En dicho molino de la "La Enrea» también Ilamado de Cañete (Turices y Zurita, 2003, p. 397) sabemos que trabajaron entre la década de 1940 y la siguientes como cagarraches algunos montefrieños como Andrés "Frangollo», "Los Charrines», "Los Cucos», Joseillo «Coronichi», Juanillo «El Changuo»... (Guzmán, 2010, p. 30).

En el año 1976 las hermanas Pedregosa vendieron la totalidad de la finca a Juan García Valenzuela, que la destinó a almacén de granos. Este, a su vez, en 1991 vendió la mitad de la misma, que comprendía la parte edificada y un trozo de patio, al Ayuntamiento de Montefrío, que tras varias reformas llegó a convertirla en lo que hoy es el "Hotel La Enrea», y la parte restante del patio finalmente fue vendida a la Unión Panadera Montefrieña para dedicarlo a almacén. El «parking» del hotel está ubicado en lo que fue el patio y acceso del Molino de la Cueva.

${ }^{23}$ Diario Patria día 30 de marzo de 1955. 


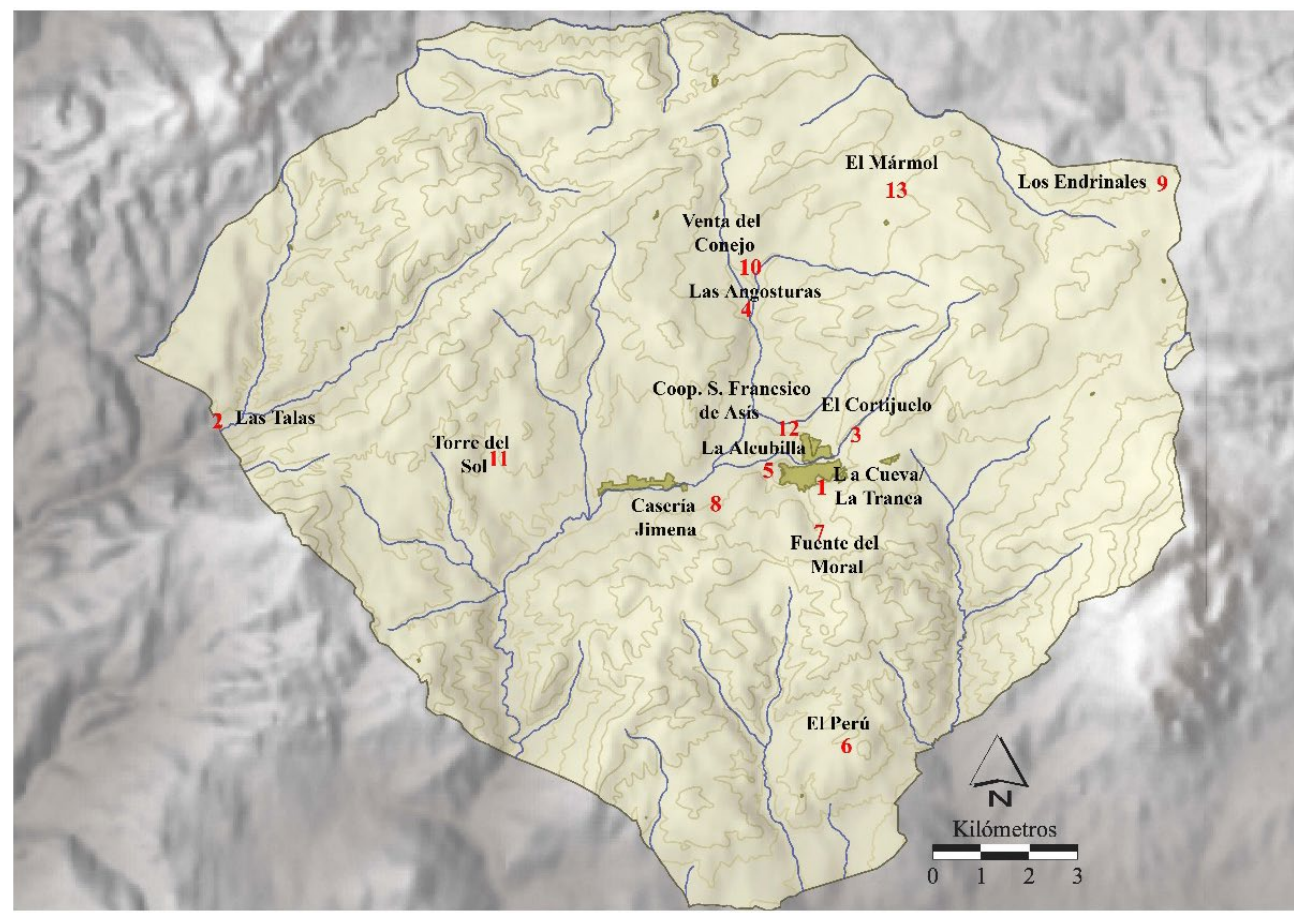

Figura 15. Molinos de aceite en el término municipal de Montefrío ${ }^{24}$.

\subsection{El molino de aceite las Talas (conocido también como de las Manillas)}

En el "Padrón General del Vecindario» de 1834, en el partido de Turca, figura un molino de aceite cuyo molinero era Antonio Martín Cortacero, que lo habitaba con su esposa y sus dos hijos. En los de 1838 y 1845 estaba habitado por Francisco Escobar, su esposa Antonia Gámez y los hijos de ambos, en los de 1848 y 1854 por Antonio Ramírez, su esposa Francisca Bárbara y algunos hijos pequeños de estos, y en el de 1867 por Antonio Cañadas, Antonia Espinosa y sus tres hijos ${ }^{25}$. Debe tratarse del molino mencionado por Madoz a mediados del siglo XIX en el referido partido de Turca. Se ubica entre la actual carretera A-4154 (P.K. 32.2), -antigua N.321- y el Rio Turca, a escasos metros del límite del término municipal con el de Algarinejo. De su tipología sabemos que se trataba de un molino de viga que también es mencionado en padrones de riqueza bajo la titularidad de Josefa Valverde Escobar en el año 1883, con una prensa para aceite en Turca, y la de Cristóbal Cubero Solís en los

${ }^{24}$ Los molinos numerados en el mapa con los números $12-13$, son molinos o fábricas que surgieron a partir de la segunda mitad del siglo $\mathrm{xx}$, y que no trataremos aquí.

${ }^{25}$ AMM. 5.6. Padrón de habitantes de Montefrío, consulta diversos años 1834, 1838, 1845, 1848,1854 y 1867. 


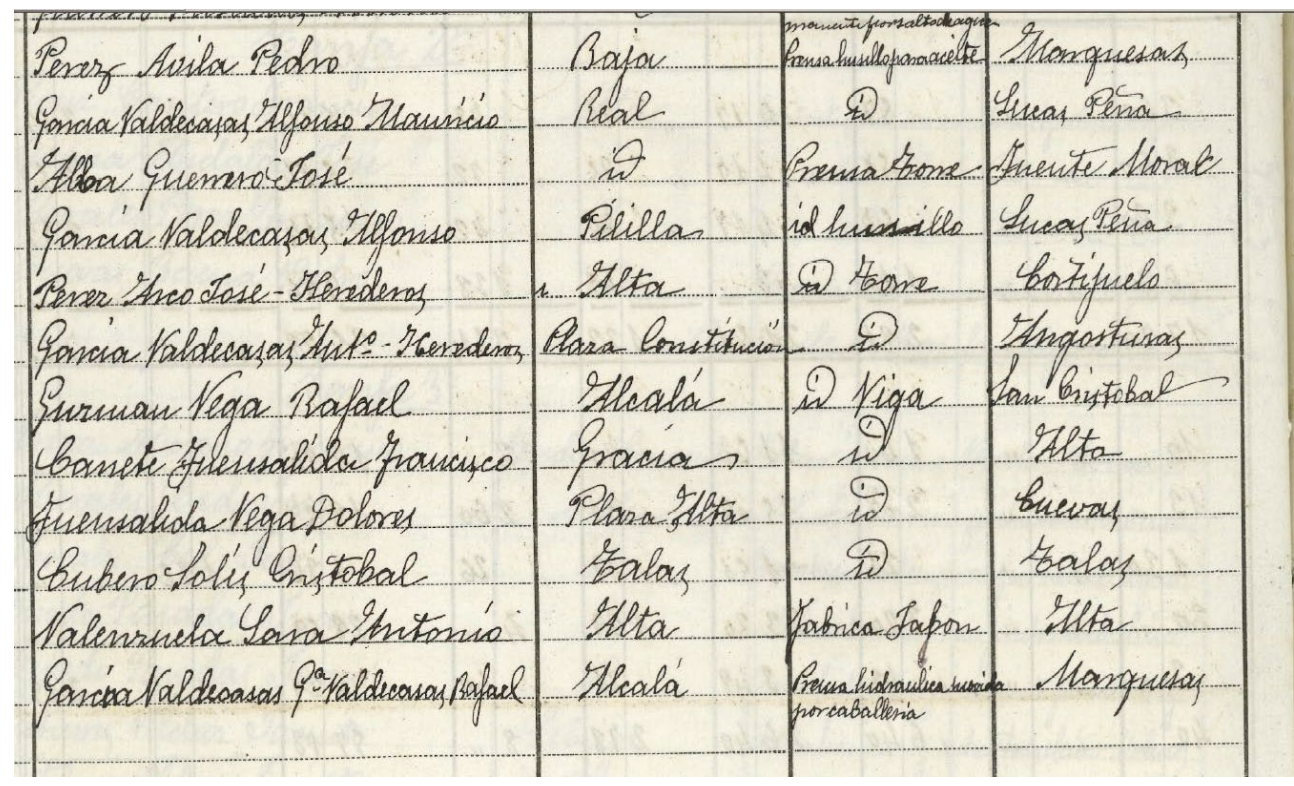

Figura 16. Listado de molinos aceiteros en 1906 (Fuente: AMM. Impuestos Estatales Padrón de riqueza territorial. Caja 1, año 1906).

de 1906 a 1909. Igualmente aparece mencionado en la información recogida en el Plano Topográfico del Instituto Geográfico referente al año 1925, y en una relación elaborada por la Secretaría del Ayuntamiento de Montefrío de 15 de febrero de 1940 (ver Figura 31), sobre «molinos aceiteros y fábricas de aceite de oliva» como molino de aceite en las "Manillas» ${ }^{26}$.

En concreto en varios padrones de vecinos se hace mención a este molino en el partido del Arroyo de Turca, regentado por Antonia Capilla en 1834, por José Adamuz Sánchez y Francisca Adamuz en 1838 y 1845, por José Lorenzo Delgado y Antonia Padilla en 1848, por Domingo León Plasas y Ramona Perea en 1854. En 1865 aparece citado como molino de aceite "Manillas» siendo ocupado por Antonio Cañadas y su familia. Poco después, por Antonio Redondo y María del Puerto en 1867. El molino de aceite vuelve a ser mencionado en 1875 , siendo sus vecinos José Antonio Martín y Bernarda Ortuño. En 1910 aparece recogido como molino "Cubero», ocupado por Manuel García Campaña y Juliana Martín Cano. Este molino parece que siguió estando en uso hasta bien entrado el pasado siglo Xx.

En la actualidad del molino aceitero solo quedan sus ruinas invadidas por vegetación, de las que destaca el arco del acueducto y el cubo de entrada de agua, así como algunos tramos de la acequia que con agua del Rio Turca (procedentes en su

${ }^{26}$ AMM. Sala A. Estantería 10. 9.1.2. Miscelánea del Sector Agrario. Decalvación de reservas de aceite año 1941-1942. 


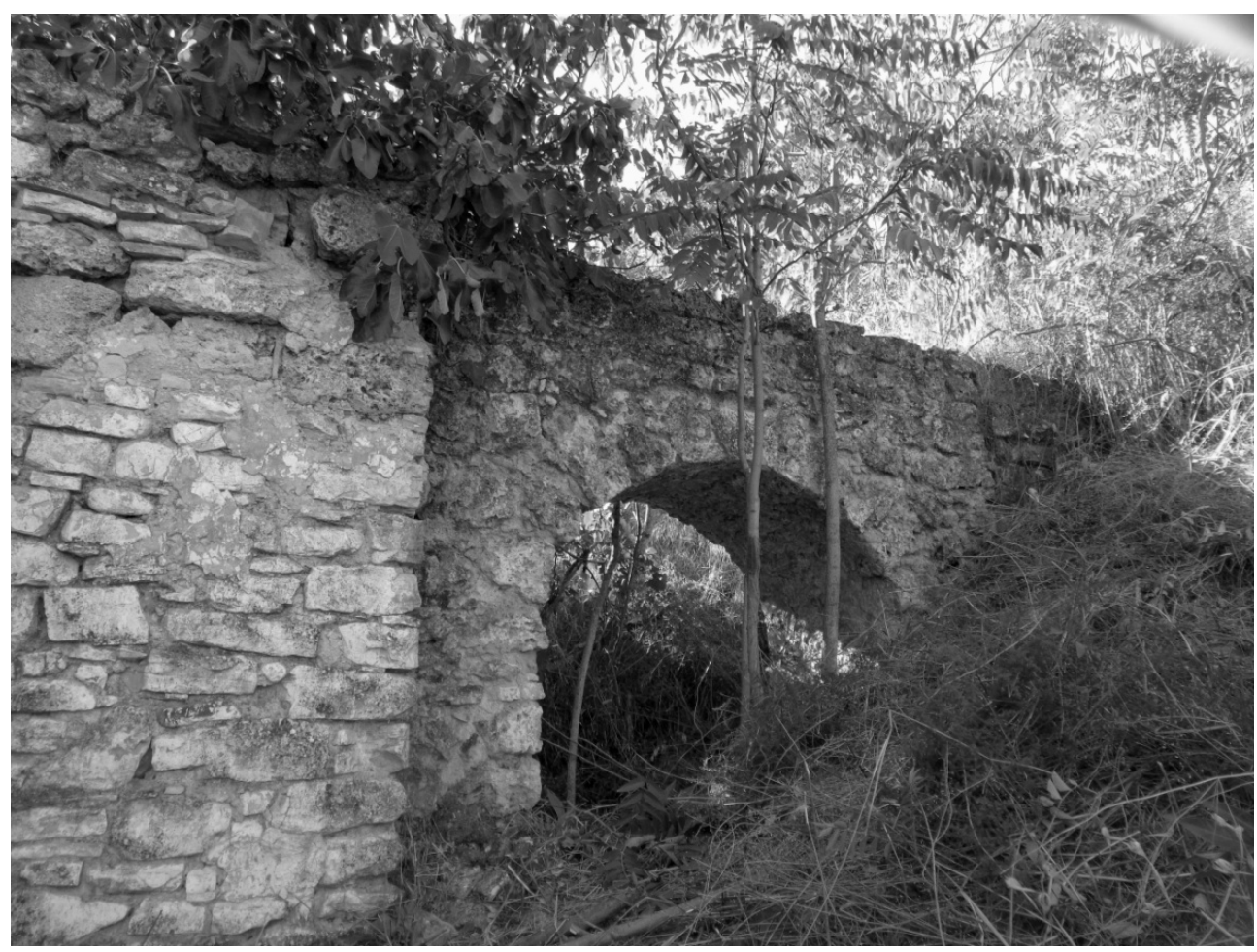

Figura 17. Acueducto y cubo de entrada de agua al Molino Cubero. (Foto: Felipe Jiménez).

mayor parte del Arroyo de las Manillas o Navavieja) generaba la fuerza motriz para moler al principio e incluso para mover la prensa hidráulica (por salto de agua)en su última etapa (1938-1945), en la que lo Ilevaba Antonia Cáliz Arco. En la actualidad al parecer se le sigue denominando «Molino Cubero».

\subsection{Molino de aceite El Cortijuelo}

La existencia de este molino no ha perdurado en la memoria histórica colectiva por lo que se ha sabido de su existencia gracias a la documentación sobre los padrones de riqueza y de vecinos de Montefrío conservados en el archivo del Ayuntamiento. Su origen parece estar documentado en 1883 a nombre de los herederos de José Pérez Arco. Era un molino de torre según se desprende de los listados de contribución industrial de 1906 a 1908 que existen en dicho archivo ${ }^{27}$. Además, de la información recogida en el plano topográfico Instituto Geográfico $^{28}$, en la información referente al campo, en el año 1925 seguía siendo propiedad de los referidos

27 AMM. 5.4 Impuestos Estatales Padrón de riqueza territorial. Caja 1, años 1906-1908.

28 Planos del Instituto Geográfico de 1925 Término de Montefrío Provincia de Granada. 
herederos de José Pérez Arco, debiendo a partir de esa fecha dejar de existir como tal, ya que no hay constancia del mismo en la demás documentación consultada.

\subsection{Fábrica de aceite Las Angosturas}

En la zona de Las Angosturas sabemos que existió un molino harinero hidráulico que aprovechaba el agua procedente del arroyo que en ese punto se conoce por el mismo nombre, aunque aguas abajo su nombre sea el de Vilanos. El origen de este molino lo desconocemos, aunque parece que podría tratarse del molino que se menciona en un lote de tierras que adquirió la abadía del Sacro Monte en dicha zona ya en el siglo XVII (Padilla y Pedregosa, 2013, p. 321). Dicho molino aparece reflejado en la cartografía antigua, y sabemos que tuvo un alambique de aguardiente con cuadras, pajar y patio. Así mismo es uno de los molinos de aceite que menciona Madoz a mediados del siglo XIX.

El paso del tiempo y el cambio en la economía montefrieña harán que el molino de las Angosturas pase de ser harinero a convertirse en fábrica de aceite. Este molino ya figuraba como tal en el padrón de habitantes de 1849 , siendo sus moradores la familia Coca Padilla y en el de 1851 lo habitaba una hija de dicha familia, M. - Francisca Coca, y su marido Manuel Pedregosa. En 1858 figura como «molino de torre». Era propiedad de la familia García Valdecasas, siendo sus propietarios en estas fechas D. José María y D. Rafael, en 1870 lo heredó don José García Valdecasas y Guerrero. Desde entonces y hasta su venta perteneció a distintos herederos de la familia García Valdecasas.

El molino es mencionado en los padrones de riqueza de 1906-1909 como propiedad de los herederos de Antonio García Valdecasas, al igual que en el listado a 15 de febrero de 1940 (ver Figura 31) realizado por el Ayuntamiento de Montefrío que lo denomina fábrica de aceite propiedad de D. Rafael García-Valdecasas y Fuensalida $^{29}$. A partir de 1928 el molino contaba con una prensa hidráulica movida por caballerías, también para el movimiento de la prensa el molino tuvo un motor de vapor entre 1929-30 hasta que parece que se abandonó en 1945. El molino aceitero constaba de bodegas con capacidad para catorce tinajas, alambique de aguardiente, cuadras, pajar y patio con veinticuatro trojes ${ }^{30}$.

\subsection{Fábrica de aceite Alcubilla-Tenerías}

El antiguo molino de la Alcubilla o también conocido como el de las Tenerías se ubica fuera de la villa, en el antiguo camino que iría a Loja, a escasos metros de

${ }^{29}$ AMM. 5.4 Impuestos Estatales Padrón de riqueza territorial. Caja 1, años 1906-1908.

30 Nota simple informativa de la Finca de Montefrío 1768, número 18009000317827, Registro de la Propiedad de Montefrío 3 de julio de 2017. 
la zona de las Erillas, en la encrucijada formada por el arroyo de la Cruz Gorda o de la Tranca con la actual carretera, en cuyo entorno se encuentran una serie de casas, conocidas como Alcubilla, a espaldas de la muralla exterior del castillo de Montefrío.

Dicho topónimo deriva del ár. al-qubba, y nos habla de una zona de producción, consistente en una serie de huertas y un molino hidráulico (conservándose tan solo parte del caz, presa, cubo, y los huecos de los cárcavos de dicha estructura). Además, existen una serie de recortes labrados en la roca, a modo de piletas o depósitos, que tendrían la función de contener el agua, bien para almacenarla o conducirla al cubo del molino (Pedregosa, 2012, p. 97). El topónimo qubba o alcubilla está presente en diversas zonas de la geografía peninsular, por ejemplo, en la zona de Toledo, en la provincia de Málaga, en Antequera aparece una alcobilla alta y una alcobilla baja en el Libro de Repartimientos, también en Cártama se conoce la existencia de un arroyo de la alcubilla. Martínez Enamorado vincula estos topónimos con hidrónimos relacionados con pozos, como comprueba en el repartimiento de Málaga o en el pago de Alcoba de Algarrobo, «aunque derivados del árabe, de fundación castellana» (Martínez, 2003, p. 276). En este sentido, Oliver Pérez lleva a relacionar esas Alcubillas en Cubillas y Alcoba con construcciones hidráulicas, sobre todo, con arcadas de agua (Oliver, 1993, pp. 175-176, 178). Cómo advierten dichos autores, estos topónimos, se conocen en el siglo XV, en vísperas de la conquista castellana, quizás por ser construcciones realizadas por los moriscos que conocían su funcionamiento. Para el caso de Montefrío, su origen iría vinculado a la conquista de la villa en 1486, ya que las fuentes y crónicas no mencionan su existencia.

En un primer momento el molino de La Alcubilla fue harinero, y constaba de dos paradas con su estanque, cabeza de aprecios, y dos cauces o acequias, una de las cuales conduce el agua del arroyo del Membrillar, Cruz del Jabonero o de los Muladares, que la toma por el paraje de este último nombre y otra del arroyo de la Tranca, tomando el agua del barranco que desemboca en dicho arroyo, cuya toma se hace por medio de una canal. El molino tenía dos pisos, alto y bajo, una alameda, olivos, salto de agua y un estanque, estando instalados en las diferentes dependencias de que consta el edificio, el motor y transformador eléctricos y demás útiles y aparatos necesarios para la fabricación de harinas además de un horno de pan cocer. El molino estaba atravesado por una acequia que pasaba junto al edificio, que conduce las aguas desde el citado arroyo de la Tranca tomándolas por bajo de la presa del molino a la huerta de la Alcubilla para el riego de esta. Hay además dentro de la finca dos pilares pequeños, uno dentro del edificio donde estaba el horno y otro fuera de la parte edificada, ambos de agua potable que procede de unos tajos que hay frente al molino, donde se encuentran dos nacimientos, el agua era conducida por tuberías de plomo, desde un embalse que todavía puede verse tallado en la roca. 


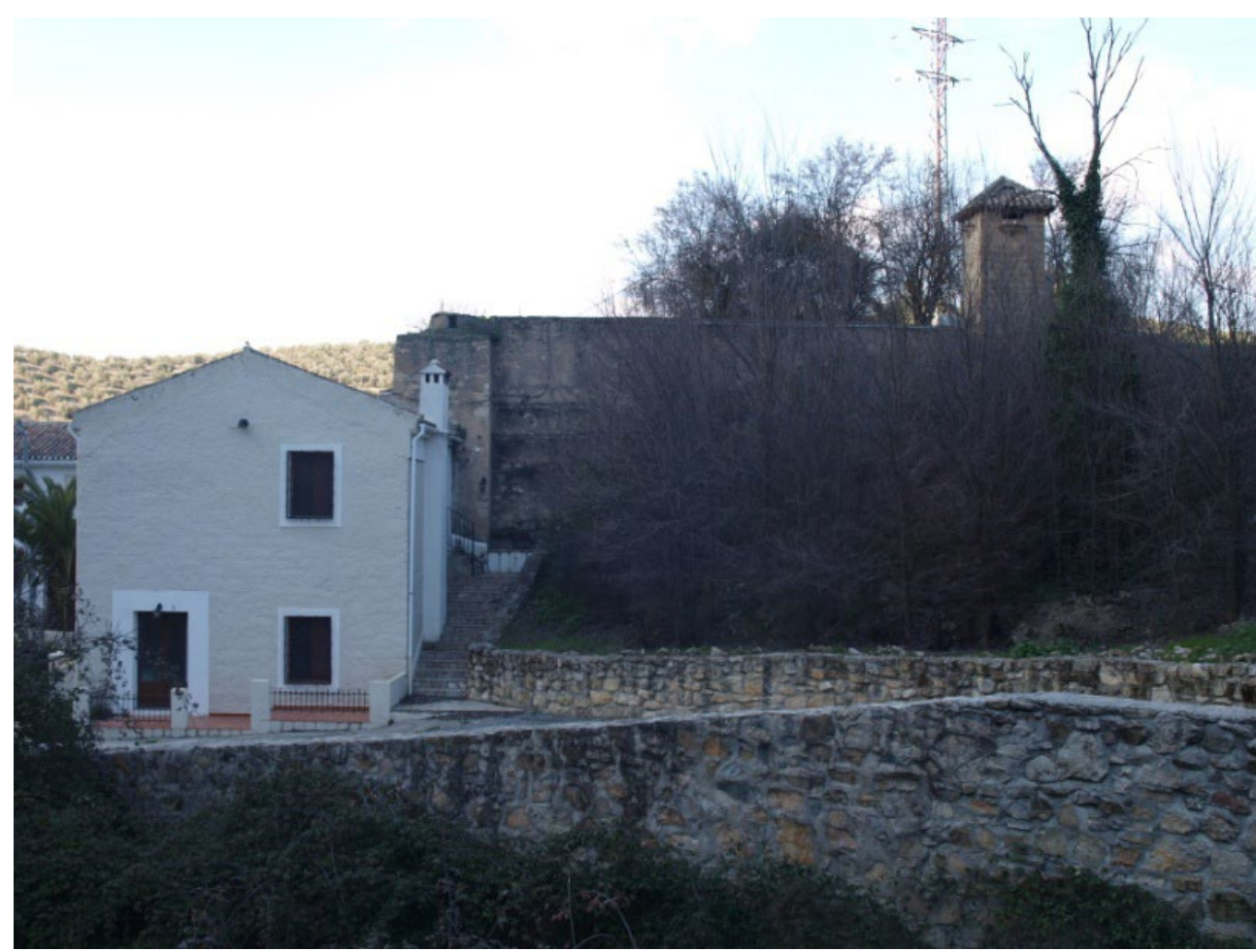

Figura 18. Molino de la Alcubilla: estancia del antiguo molino, cubo y caz. (Fuente: Pedregosa Megías).

A partir de la década de 1930, fue un molino de aceite que constaba de prensa hidráulica a vapor, aparece en los registros municipales en 1931 como propiedad de Antonio Torres Alba. En 1940 es mencionado en el listado a 15 de febrero que recoge los molinos aceiteros de Montefrío denominado como fábrica de aceite (ver Figura 31). El molino causó baja en 1948 como fábrica.

Tenemos la noticia de prensa del anuncio de este molino, al igual que otros en los años 40 del pasado siglo, que nos aporta una información valiosa, por un lado, la referente a Fábrica de aceites finos de oliva «Alcubilla», y por otro, la de una finca de olivar denominada "El Alamillo», propiedad de Antonio Torres Alba ${ }^{31}$.

Desde su origen hasta la década de 1930 el molino fue harinero, pero a partir de esa fecha, pasó a ser molino de aceite, con una explanada a su entrada principal y patio de trojes para aceituna a la espalda, compuesto de un molino de prensa de vagonetas, empiedro de dos rulos, cuerpo de bombas, termo-batidora, caldera de agua caliente, desmenuzadora, pozuelos, tinajería, depósitos y otros útiles de la

31 Diario Patria día 30 de marzo de 1955. 

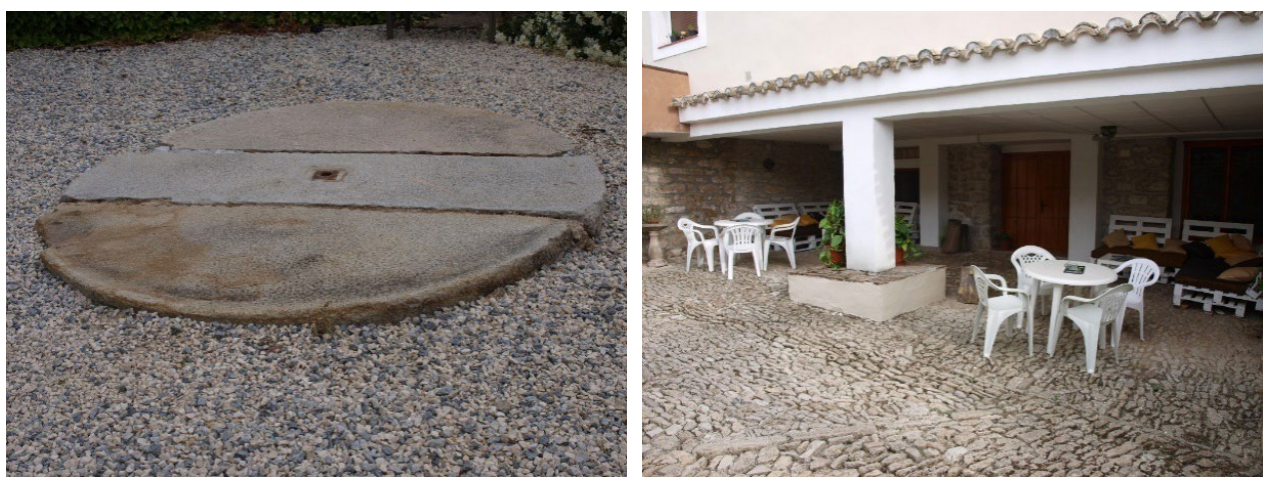

Figura 19-20. Empiedro de granito y patio para aceituna a la espalda (Fuente: Pedregosa Megías).

industria ${ }^{32}$. Utilizaba como fuerza motriz un motor eléctrico, además de una rueda hidráulica que podía accionarse por un salto de agua, que provenía del cubo del antiguo molino, así como de una red de acequias excavadas en la roca que recorre la zona de la alcubilla. En 1948 causó baja como molino retomándose como industria en 1958 bajo la propiedad de Juan Santos Osorio dejando de funcionar en 1969.

En cuanto a los propietarios, vemos cómo desde los primeros datos que poseemos destaca una de las familias más importantes de la localidad, en un primer momento podría tratarse de los Jiménez de Vega, una de las familias más beneficiadas tras la conquista de Montefrío por los Reyes Católicos, como vemos en el Libro de Apeo dos hermanos Jiménez de Vega (Jiménez, 2009), que también aparecen como propietarios de distintas fincas y propiedades en Montefrío como evidencia el Libro Becerro fechado en 1627, sobre todo en el arroyo de los Molinos, incluso el molino de Mayrena (Padilla y Pedregosa, 2013, p. 329). Quizás la evolución familiar y la unión con otra familia nobiliaria los García-Valdecasas hicieron que en un determinado momento se unieran siendo los propietarios de dicho molino de la Alcubilla desde el siglo XIX, volviéndola a adquirir la familia Vega Jiménez a partir del siglo xx.

En el padrón de vecinos tan solo contamos con varios datos claros, el primero en el año 1834, siendo vecinos Gabriel Portillo y su mujer M. siguiente dato es de 1851 Julián Cañadas y María Aguilera, en 1857, siendo vecinos Antonio Domingo Mundano y su mujer Ascensión Perea, así como varias veces más entre $1860-1905^{33}$ (ver tabla), todos estos serían arrendadores, perteneciendo

32 Nota simple informativa de la Finca de Montefrío 9355, número 18009000223258, Registro de la Propiedad de Montefrío 12 de marzo de 2012.

${ }_{33}$ AMM. 5.6. Padrón de habitantes años 1826-1910. Consultados diversos años. 


\begin{tabular}{|c|c|c|c|c|}
\hline Molino & $\begin{array}{l}\text { Año compra/ } \\
\text { venta }\end{array}$ & Propietario o Familia & Período & Vecinos o arrendatarios \\
\hline \multirow[t]{10}{*}{ Alcubilla } & & $\begin{array}{c}\text { Ramón de Vega García } \\
\text { Valdecasas }\end{array}$ & 1834 & $\begin{array}{l}\text { Gabriel Portillo y } \\
\text { M.a Teresa Cervera }\end{array}$ \\
\hline & 1871 & $\begin{array}{l}\text { Herencia Rafael y } \\
\text { Francisco de Vega }\end{array}$ & 1851 & $\begin{array}{l}\text { Julián Cañadas y } \\
\text { María Aguilera }\end{array}$ \\
\hline & 1900 & Familia Vega Giménez & 1857 & $\begin{array}{c}\text { Antonio Domingo } \\
\text { Mundano y Ascensión } \\
\text { Perea }\end{array}$ \\
\hline & 1903 & $\begin{array}{c}\text { M.a de los Dolores y } \\
\text { Margarita Vega Giménez }\end{array}$ & 1865 & $\begin{array}{c}\text { Rafael Mantas Vegas y } \\
\text { Dolores Moreno }\end{array}$ \\
\hline & 1919 & $\begin{array}{c}\text { Las anteriores y M a Josefa } \\
\text { Vega Ruiz Morón }\end{array}$ & 1875 & Ana García Marfil \\
\hline & 1926 & $\begin{array}{c}\text { M.a de los Dolores Vega } \\
\text { Giménez } \\
\text { M a Josefa Vega Ruiz } \\
\text { Morón }\end{array}$ & 1895 & $\begin{array}{c}\text { Juan Serrano Velázquez } \\
\text { y Carmen Ruiz Arroyo }\end{array}$ \\
\hline & 1926 & $\begin{array}{l}\text { Juan Ruiz Artacho y } \\
\text { Antonio Torres Alba }\end{array}$ & 1899 & $\begin{array}{l}\text { Vicente Parraga Díaz y } \\
\text { María Quintana Morales }\end{array}$ \\
\hline & 1946 & Antonio Torres Alba & 1905 & $\begin{array}{c}\text { Rafael Jiménez Fregenal } \\
\text { y Casimira Fernández } \\
\text { Cuberos }\end{array}$ \\
\hline & 1948 & $\begin{array}{l}\text { Juan Santos Osorio y } \\
\text { Plácido García Centeno }\end{array}$ & & \\
\hline & 1955 & Juan Santos Osorio & & \\
\hline
\end{tabular}

Tabla 1. Propietarios y arrendatarios molino Alcubilla (Elaboración: Pedregosa Megías).

la titularidad a los propietarios que mencionamos en la tabla. En relación con los arrendatarios del molino de aceite a lo largo de mediados del siglo $x x$ tenemos algunos datos, sobre sus trabajadores o cagarraches Juan Antonio "El Espardillao», Manuel «Polonio» o «El Rarra» (Guzmán, 2010, p. 30).

En la actualidad del antiguo molino harinero tan solo se conserva parte del caz, presa y parte de la acequia de derivación de aguas, sobre todo excavada en los afloramientos de calizas en las inmediaciones de la Alcubilla, además del cubo y estructura hidráulica derivada del mismo, los huecos de los cárcavos, aunque actualmente muy modificados. En relación con el molino de aceite, los patios para descargar las aceitunas, el empiedro de granito para la molienda, y poco más, ya que actualmente se ha rehabilitado el edificio como alojamiento rural denominado "The olive mill Alcubilla». 


\subsection{Molino de aceite Cortijo del Perú (molino Entrena)}

Este molino estaría en funcionamiento como mínimo desde 1867, ya que así consta en el registro de la propiedad. Perteneció a María Enriqueta Muñoz y Jurado, que lo deja en herencia a su hija María Araceli Jurado. En la década de 1920 pertenecía dicho molino a D. José y Dña. Araceli Entrena Amor. Según consta en documentación de archivo del Ayuntamiento de Montefrío en 1935 contaba con una prensa hidráulica movida a mano, siendo propiedad de sus hijos, y figurando como titular Juan Entrena Santaella ${ }^{34}$. Este molino es recogido en el listado que realizó el Ayuntamiento de Montefrío en 1940 (ver Figura 32), que lo denomina molino aceitero, siendo sus propietarios los herederos de José Entrena. En 1947 la finca fue comprada por Antonio Romero Bolívar, que la vendió poco después a Concepción Guerrero Mira en 1949. Con los datos que contamos no podemos precisar el momento de abandono de la actividad molinera en dicho molino.

\subsection{Molino aceitero Fuente del Moral}

Tras la reconquista, según el Libro de Apeo de 1581, uno de los primeros propietarios del paraje conocido actualmente como "Fuente del Moral», fue Alonso del Moral (Jiménez, 2009), por lo que es muy probable que el topónimo derive de esto más que de la existencia o no de algún moral en su entorno, máxime cuando los morales eran un árbol muy extendido por toda la zona y es extraño que diera nombre a un lugar concreto como si de un árbol aislado y emblemático se tratase.

En 1752, según el catastro de Ensenada (Peinado 1997), la mayor parte de las tierras de este paraje pertenecían a los «Propios de la Villa», excepto doce fanegas en las que había una construcción cubierta de retama y unos treinta olivos, que eran de la Cofradía del Santísimo Sacramento de Granada.

A mediados del siglo XIX su propietaria era doña Catalina Centeno Centeno que se lo dejó en herencia, según "partición de bienes de 22 de octubre de 1863» a doña Margarita y doña María Teresa Alba Centeno, hijas de su sobrina doña María Isabel Centeno García de La Fuente y de don Juan Alba Jiménez, con las que había convivido en su propia casa de la calle La Tranca desde 1850, e incluso ayudado a su padre a criarlas tras el fallecimiento prematuro de su madre en 1856, hasta su propio fallecimiento con 72 años en 1862.

En 1906 doña María Teresa vendió su mitad de la casa de labor y del ya existente molino a Carlos Alba Alba, hijo de su hermana doña Margarita (propietaria de la otra mitad) y de su esposo don José Alba Guerrero. En 1934, al fallecimiento de doña Margarita, su mitad se adjudicó por herencia a sus hijas doña Concepción y

${ }^{34}$ Nota simple informativa de la Finca de Montefrío 17191, número 18009000172082 , Registro de la Propiedad de Montefrío 7 marzo de 2018. 
doña Luisa Alba Alba volviendo a unificarse cuando falleció esta última y heredar su parte doña Concepción en 1957. Esta, en 1961, cedió en forma de «venta» la mitad de la que era propietaria a su sobrino don Andrés Alba Fernández de Cañete, hijo de su hermano Carlos. Finalmente, el molino y demás construcciones aledañas al mismo pasaron a ser propiedad de don Ramón Alba Fernández de Cañete que heredó una mitad de su hermano Andrés, fallecido sin descendencia, y la otra mitad de su padre...

En su documentación la construcción se describía de la siguiente forma:

Casa de teja para labor de dos piezas, bajo y alto con portal, cocina, cuadra, cámara y corral, bajo la planta superficial dicha casa de ochocientos sesenta y cuatro pies cuadrados y el corral mil novecientos ochenta y nueve, equivalentes, respectivamente, a setenta y siete metros, ciento cincuenta y cinco metros cuadrados y molino de aceite con su prensa, husillo de bronce, Torrecilla, rulo, alfanje, mortera, regaifa, pilones, patio y trojes, cañería, pilar, agua, estanques y jardín, con un cuerpo de molienda, cuatro tinajas, una sala pequeña por encima de la molienda, cuadra y pajar que tiene por separado para servicio del molino y de la casa de labor, bajo la planta superficial de dos mil doscientos veintitrés pies cuadrados, equivalentes a ciento setenta y un metros cuadrados $^{35}$.

El molino de la Fuente del Moral, como se desprende de su descripción inicial, era un molino con prensa de torre, que ya estaba en funcionamiento en la década de 1840, tras la descripción que hizo Pascual Madoz. El molino aparece mencionado en los padrones de riqueza de 1883, 1906-1909, el titular y encargado del mismo era don José Alba Guerrero. Posteriormente es mencionado en el plano topográfico del Instituto Geográfico referente al campo en el año $1925^{36}$. Se incluye en el repetido listado de 15 de febrero de 1940 del Ayuntamiento de Montefrío (ver Figura 31), figurando como molino de aceite y siendo sus titulares los «Hijos de Don Carlos Alba».

El molino, como todo ingenio, fue evolucionando con el tiempo; en su origen fue, como se ha dicho, un molino de torre, pero ante los avances tecnológicos irá adaptando su mecanismos e ingenios. Así, a partir de 1928 el molino contaba con una prensa hidráulica movida por caballerías hasta su abandono como molino en 1945. Su construcción se conserva en buen estado, estando organizada en dos dependencias claras, una destinada a vivienda, a la que le precede un jardín, y otra destinada a almazara.

35 Nota simple informativa de la Finca de Montefrío 4138, número 18009000353108, Registro de la Propiedad de Montefrío 5 julio de 2017.

${ }^{36}$ Planos del Instituto Geográfico de 1925 Término de Montefrío Provincia de Granada. 


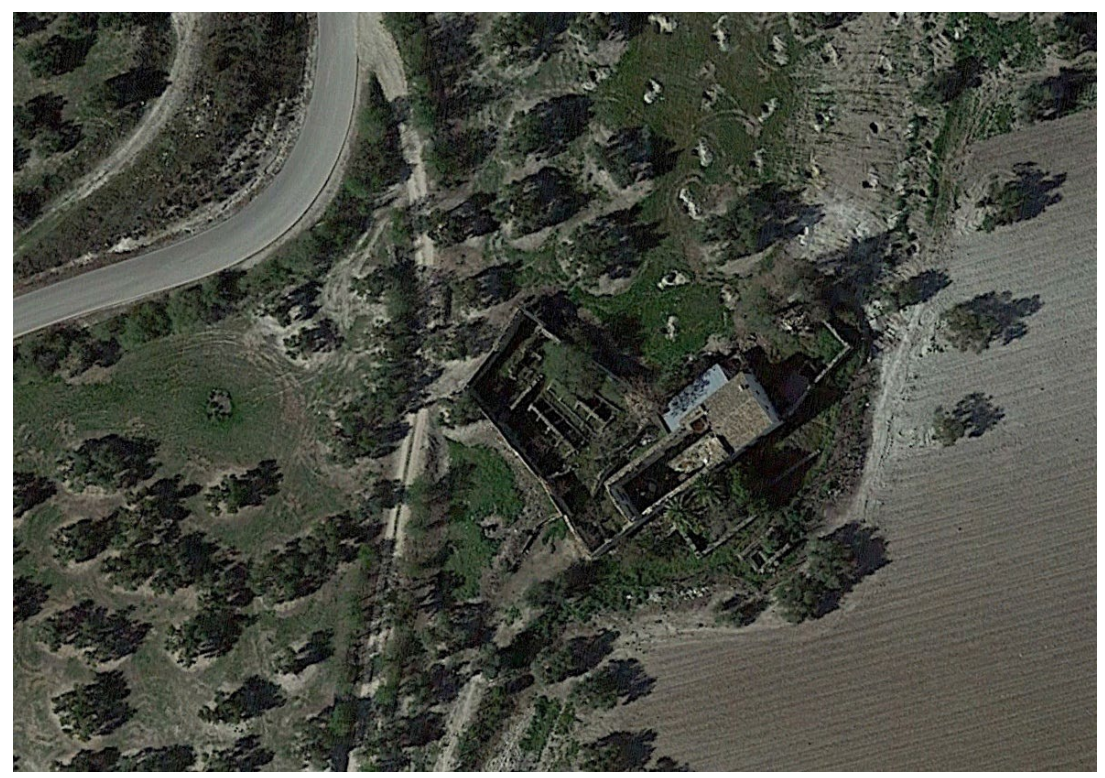

Figura 21. Fotografía aérea del Molino de la Fuente del Moral. Se aprecian el patio de trojes, la nave de molienda y prensado, y otras dependencias (Fuente: Google Earth consulta 3/29/2016).

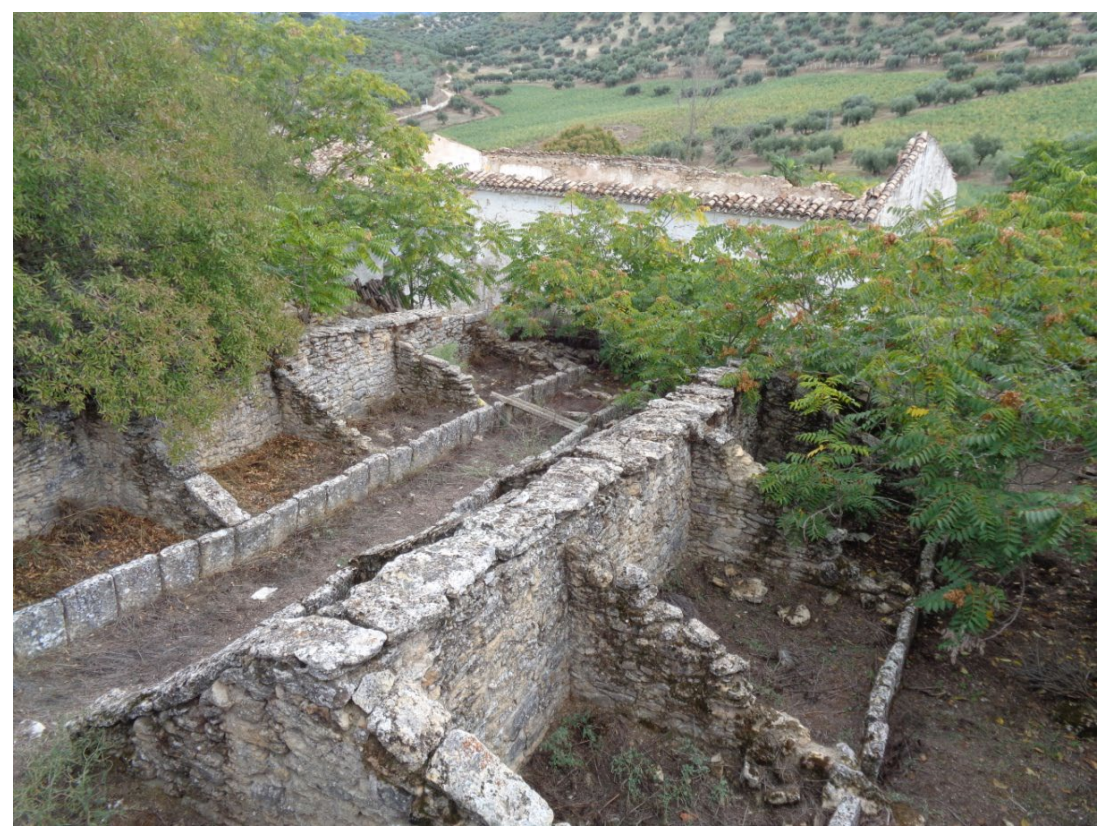

Figura 22. Patio del molino con las trojes (Fuente: Felipe Jiménez) 


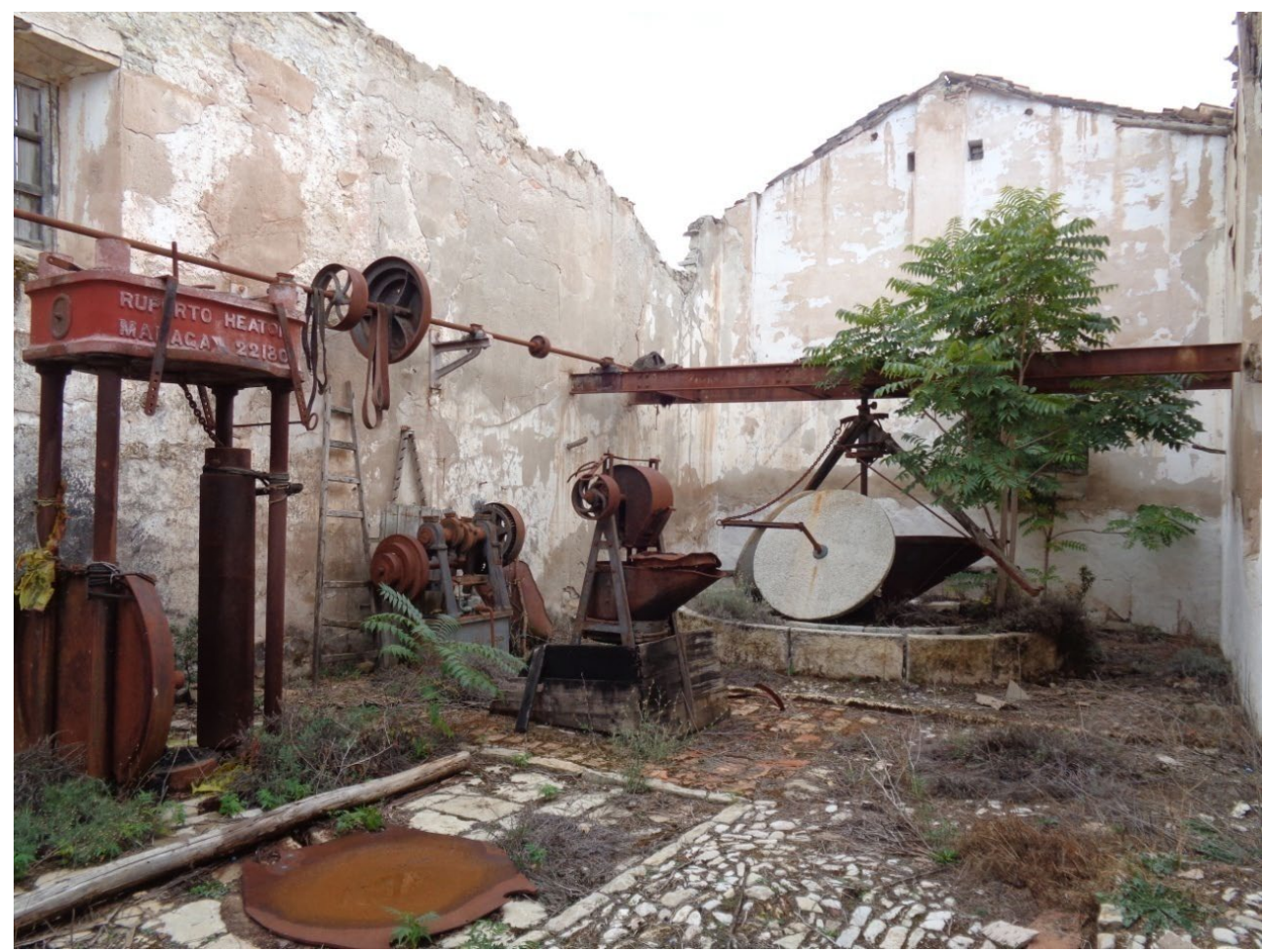

Figura 23. Prensa Hidráulica con su cuerpo de bombas, alfarje compuesto empiedro, rulos y tolva, para ser movidos por caballerías. (Fuente: Felipe Jiménez).

En la trasera se sitúa el patio de trojes, pequeños receptáculos de aceituna, construidos con muretes de fábrica en talud dispuestos en hilera facilitando el almacenamiento y utilización de los cargos. El prensado se realiza mediante una de las prensas denominadas d bombín, y el vertido del alpechín se canalizaba al exterior por unas decantadoras situadas ante el pequeño jardín (Turcies y 'Zurita, 1993, pp. 396-397).

En este molino trabajaron «Los Mamullos» hasta su cierre (Guzmán, 2010).

\subsection{Molino de aceite Casería "La Jimena»}

Este molino de aceite se ubica en el campo, en la zona de los Hundieros, la Umbría y Milanos; parece que su funcionamiento sería anterior a 1897, fecha que se encuentra en una cartela en la puerta de entrada de la fábrica. Los datos recogidos en documentos del Ayuntamiento de Montefrío lo sitúan en 1928 como un molino de prensa hidráulica movido a vapor propiedad de Manuel Guzmán Pasadas. A partir de 1940 el molino contaría con una prensa hidráulica movida por electricidad, 


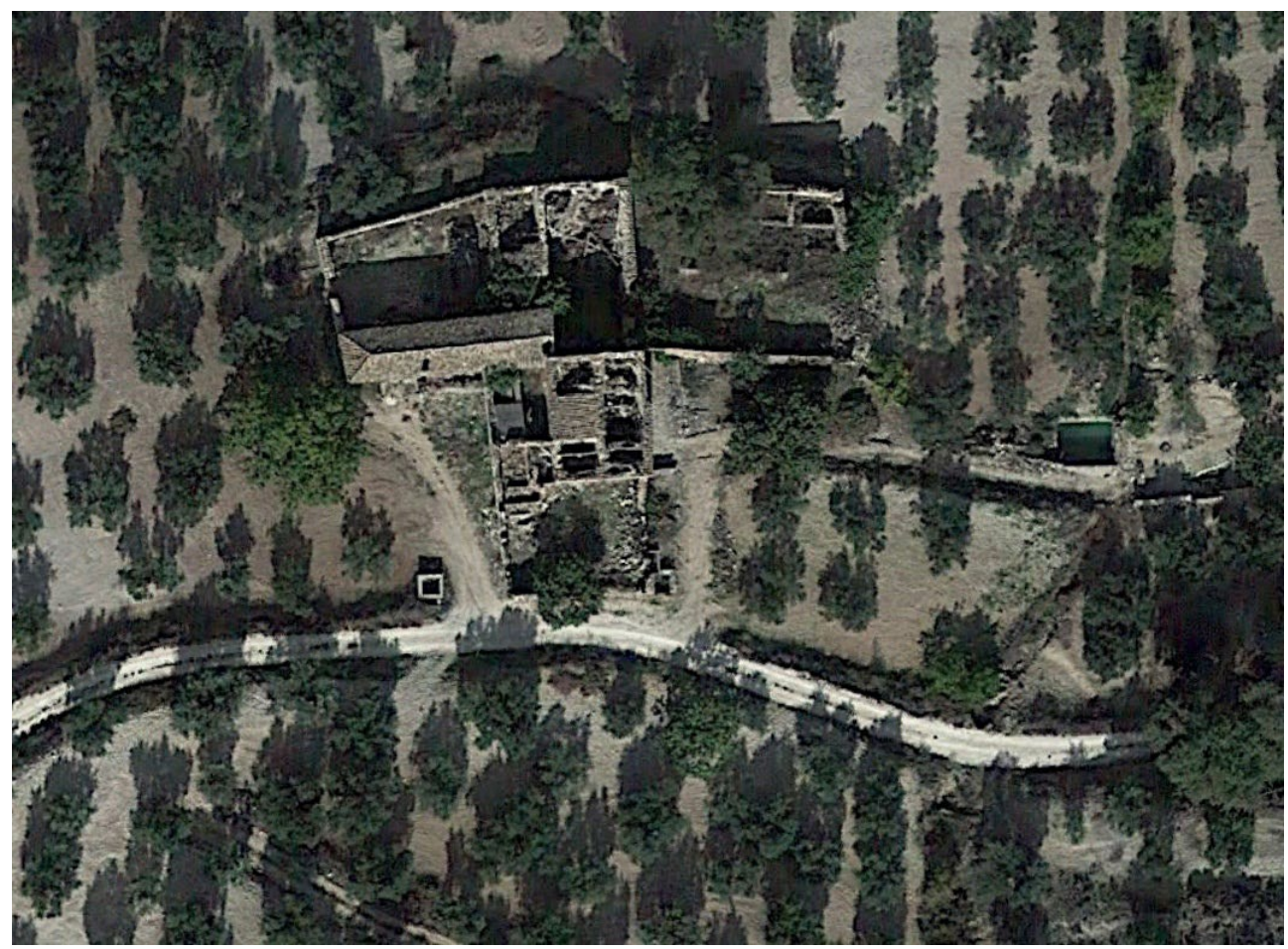

Figurea 24. Fotografía aérea de La Casería Jimena. Se aprecia la estructura del molino. Se observan en primer plano los trojes, y el edificio donde se localiza la prensa y el molino. (Fuente: Google Earth consulta 3/29/2016).

siendo el molino propiedad de Pedro Arco Pérez. En 1942 el molino sería movido por gasolina y cambiaría de dueño, siendo José Pulido Conde. Este molino no es recogido en el listado de 1940 realizado por el Ayuntamiento de Montefrío de las industrias molineras vinculadas al aceite (ver Figura 31). A partir de 1955 perteneció la Casería a Cristóbal Granados Malagón. Este molino era conocido como «La Casería de los Guzmanes» y en ella trabajaron «Los Marmullos» (Guzmán, 2010).

La Casería Jimena estaba compuesta por 84 fanegas ( 39 ha), en sus inmediaciones existen tres manantiales, que servían para el riego de tierras, en él se enclava un edificio casería y una fábrica de aceites movida por un motor de aceite pesado (tipo Garde-Vellido), la fábrica consta de un empiedro salipé (piedra berroqueña de la sierra norte de Córdoba, similar a los granitos, conocida con el nombre común de "Salipé» o "Granito Rosa»), alfarje y depósitos de masa de chapa, cuerpo de bombas, prensa hidráulica de unos $800 \mathrm{~kg}$, bodega, veinte tinajas y depósitos de chapa de unas 800 arrobas, patio de trojes, pajares y cuadras, ocupando toda la edificación $1127 \mathrm{~m}^{2}$. En el entorno tenía un estanque, además de tres eras para trillar mieses, y junto a la casería un pilar y una fuente que surtían de agua tanto a 
la industria como a las necesidades humanas ${ }^{37}$. Se conservan sus ruinas en las que aún se pueden observar algunos de los elementos citados.

\subsection{Fábrica de aceite Los Endrinales}

La fábrica de aceite de Los Endrinales se localizaría en la zona de los Hospitales, al noreste del término municipal de Montefrío, en el límite del mismo, por lo que al norte limita con la provincia de Jaén (Alcalá la Real) y al este con el municipio de íllora (Granda). El carril de acceso parte de la Cañada Real de Granada a Córdoba a la altura del paraje denominado Cruz de Matute.

Al igual que en otros casos, de esta fábrica de aceites es poca la información que se conserva, sobre todo contamos con datos de archivo conservados en el Ayuntamiento de Montefrío. Se trataba de un molino con prensa hidráulica movida por caballerías y que era propiedad de Laureano Ramírez Coca en 1938; dicho molino causó baja en 1946 en el registro de las industrias aceiteras. A partir de 1948, aparece dicha fábrica de aceites siendo el titular Rafael Ramírez Coca dejando de figurar en dichos registros en 1968. Igualmente figura en 1940 (ver Figura 31) en el listado de 15 de febrero que recoge los molinos aceiteros de Montefrío como fábrica de aceite, siendo su titular don Laureano Ramírez Coca ${ }^{38}$.

\subsection{Molino Venta del Conejo (inicialmente se denominó fábrica de aceites San Francisco)}

Una primera descripción de este molino dice así; se ubica en el paraje de Las Angosturas y Sandoval, el edificio cuenta con una superficie de $550 \mathrm{~m}^{2}$, dos cuerpos de alzada, cobertizos y patio, cercado todo ello con una tapia, en total cuenta con una extensión de $1600 \mathrm{~m}^{2}$. La vivienda tiene planta baja y alta. En la baja se ubicaba la instalación de un complejo industrial, compuesto de fábrica de aceite con cuatro prensas, que con el paso del tiempo fueron tres, además llego a tener un extractor de aceite de orujo y varias instalaciones anejas a la misma ${ }^{39}$.

El molino parece que tiene su origen en la década de 1950, siendo propiedad de la familia Bermúdez López. A partir de 1961 sus propietarios serán Julián Bermúdez Pérez y su esposa. La fábrica sufriría reformas en sus instalaciones y maquinaria, siendo sus dependencias un cobertizo, y contaba con un moledero, dos termo

37 Nota simple informativa de la Finca de Montefrío 14545, número 18009000198938, Registro de la Propiedad de Montefrío 9 marzo de 2018.

${ }^{38}$ AMM. Sala A. Estantería 10.9.1.2. Miscelánea del sector agrario. Declaraciñin de Reservas de Aceite (1941-1942).

39 Nota simple informativa de la Finca de Montefrío 13485, número 18009000102546, Registro de la Propiedad de Montefrío 5 julio de 2017. 
batidoras, dos prensas y sus cuerpos de bomba, además de varios motores, oficina, aclaradores, jámilas o jamileras y almacén para varios depósitos de aceite. El molino contaba en su lado SO con un transformador de luz eléctrica y una tapia que cerraba todo el edificio y sus patios en una extensión total de $1600 \mathrm{~m}^{2}$. No obstante, y por problemas financieros de su propietario, que acarrearon una de las «quiebras» más sonadas en nuestro municipio, a mediados de la década de los sesenta esta fábrica dejó de funcionar.

Este molino en origen fue denominado como Fábrica de San Francisco de Asís en honor a su primer propietario Francisco Bermúdez López ${ }^{40}$, tras la quiebra, intentaron comprar dicha almazara los fundadores de la actual cooperativa de San Francisco de Asís, de ahí que utilizarán después dicho nombre para la posterior fábrica al fracasar la compra de esta, fundándose posteriormente la cooperativa de San Francisco de Asís en la zona del jabonero próxima al núcleo de Montefrío.

En el molino de la «Venta del Conejo» trabajaron diversos montefrieños como Antonio "Tres Huevos», Cristóbal "Salas», "El Chato la Pavera», Diego "Cabezapelá», José «El Cuesco», Juanillo «Casiano», López «La Criatura», Raimundo (Guzmán, 2010).

Las instalaciones fueron vendidas por los síndicos encargados del proceso de liquidación a los hermanos Pérez Moreno (dos) y un primo de estos, Francisco Moreno Perálvarez, en 1973, que junto con otros dos socios posteriores la pusieron en funcionamiento y modernizaron paulatinamente, sustituyendo el molino de cuatro rulos, de los más grandes de los que hubo en los molinos montefrieños, por uno de martillos con su termo batidora, un montador automático de cargo, ampliando el número de prensas hasta cuatro.

El cofín o capacho era una pieza fundamental en el proceso de prensado del aceite, ya que la pasta del mismo se vertía entre cofín y cofín. También se conocía como esportín, capacho o baleo; se trata de un cesto o canasto, utilizado en el proceso de tradicional de obtención de aceite. Este recipiente viene utilizándose desde época romana, empezando a decaer su uso en la segunda mitad del siglo Xx con la aparición de las modernas almazaras que obtienen el aceite mediante el centrifugado de la pasta de aceituna. El cofín era la pieza volante que se utilizaba en las fases de batido y prensado (Sánchez, 2018, p. 335), dentro del proceso tradicional de obtención de aceite: molturado, batido, prensado, decantado y almacenado.

Destaca un reciente trabajo de Sánchez Carré sobre la realización de confines o capachos, en el que se describe los materiales usados tanto fibras naturales como el esparto o coco, así como otras fibras sintéticas polipropileno o nylon. El diámetro de estos variaba según el diámetro de la prensa en $30,40,50,60,70,80 \mathrm{~cm}$, frente al orificio en el centro de su radio o fabricación que oscila entre los $8-10 \mathrm{~cm}$, este tipo

${ }^{40}$ Queremos agradecer a Paco Peregrina Blanco la información referente a la cooperativa de Nuestra Señora de los Remedios, así como fotografías y noticias de prensa. 

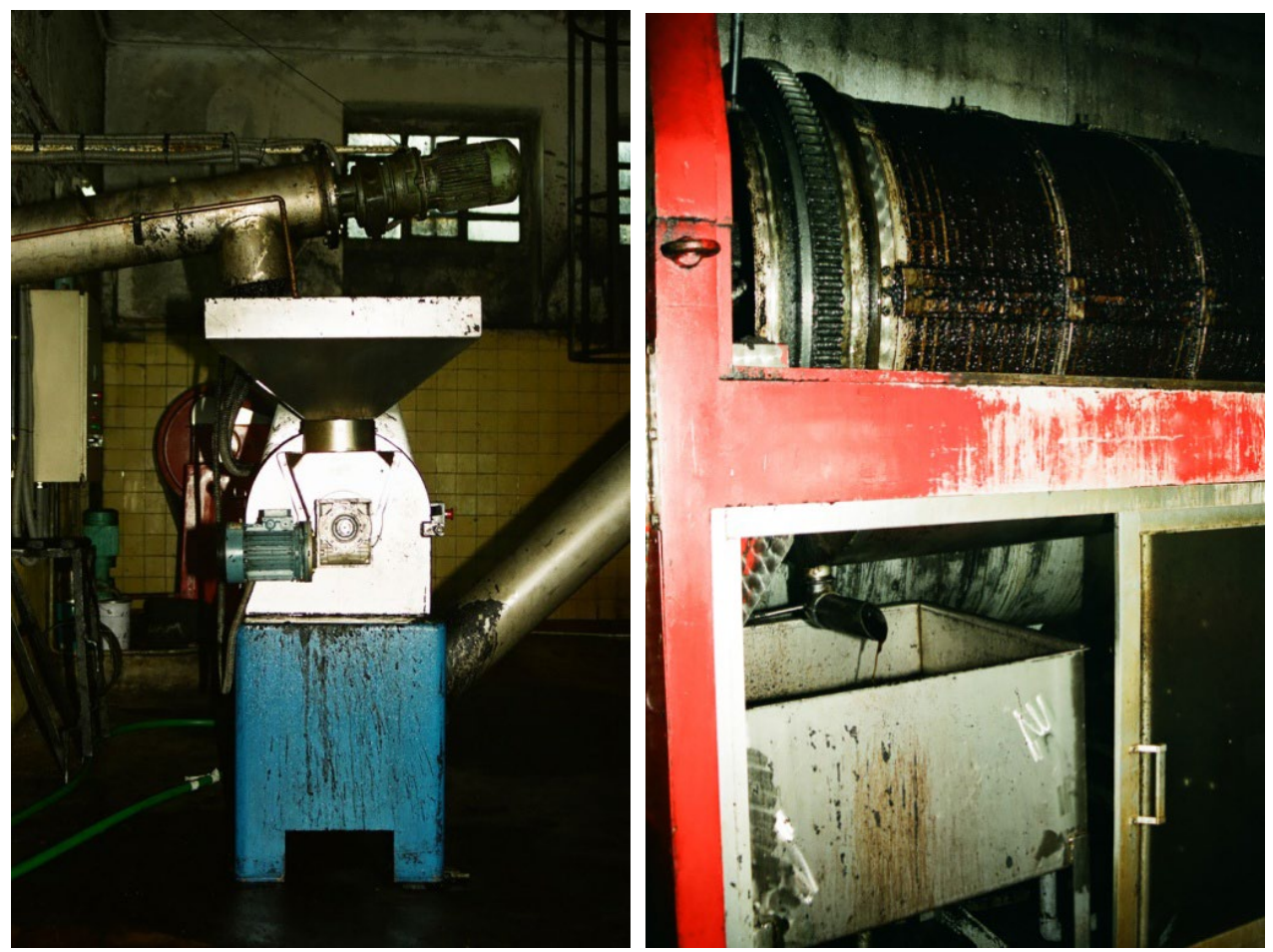

Figura 25-26. Molino de martillos y termo batidora. (Fuente: Gerardo Moreno).

de piezas se dividen en la cobija o la capachera, que son distintas. La cobija lleva una solapa o vuelta en el borde para contener la pasta de la aceituna y que no se salga, esta iría abajo y encima la capachera que sería el confín sin cobija, y taparía el relleno de la pasta (Sánchez, 2018, p. 335).

En 1993 se constituye la cooperativa «Almazara Nuestra Señora de los Remedios» que, primero en régimen de alquiler y a los pocos años como propietaria, pasó a explotar esta fábrica de aceite. Actualmente es una de las dos cooperativas de este tipo que existen en el municipio.

Se ha dotado de maquinaria avanzada e instalaciones que permiten que, con su doble línea de lavado y tolvas con capacidad de $60000 \mathrm{~kg}$, la aceituna sea molida en el menor tiempo posible desde su entrada en la almazara. Las antiguas prensas fueron sustituidas por lo que actualmente se conoce como sistema continuo para la extracción del aceite, con sus correspondientes batidoras y posterior centrifugación horizontal (decanter) y vertical para obtener un aceite de primerísima calidad que se almacena directamente en la zona de bodega, en la que se sustituyeron los antiguos depósitos de chapa por depósitos de gran capacidad de acero inoxidable.

En 2010 se integró en la cooperativa de 2. grado «Aceites de Granada, Tierras Altas» y desde 2013, tras la fusión de Tierras Altas con el grupo Hojiblanca 

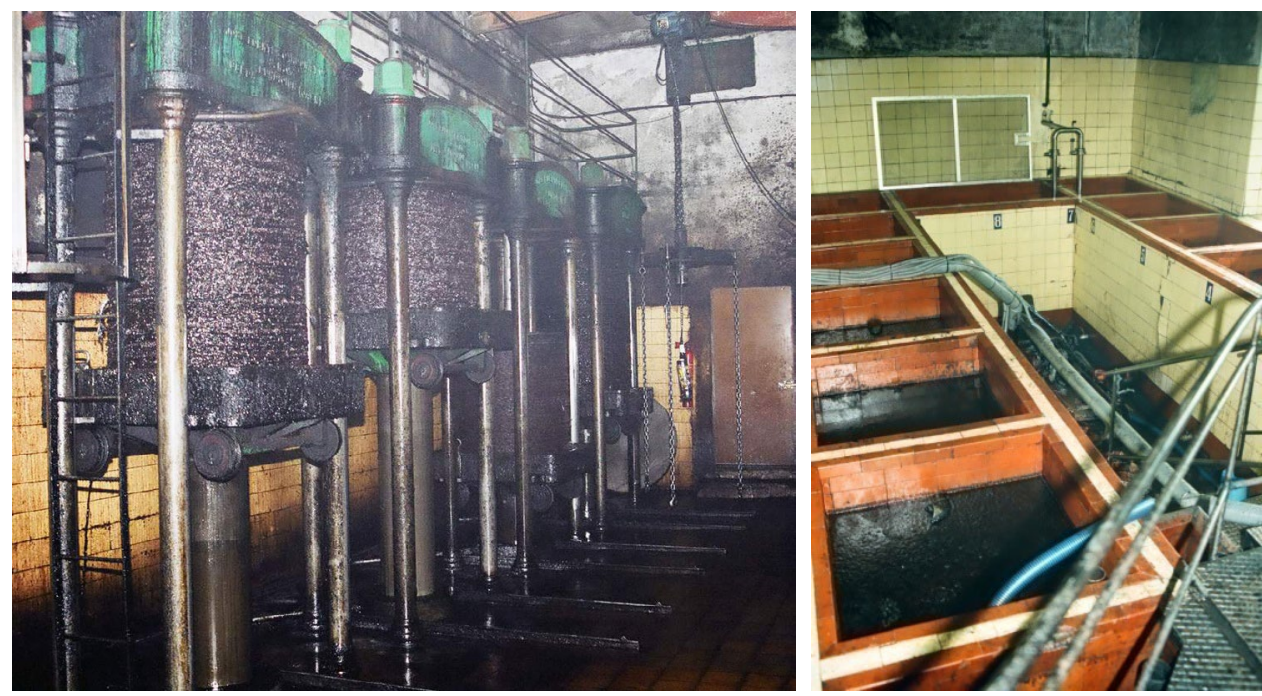

Figura 27-28. Prensas y pozuelos de decantación. (Fuente: Gerardo Moreno).
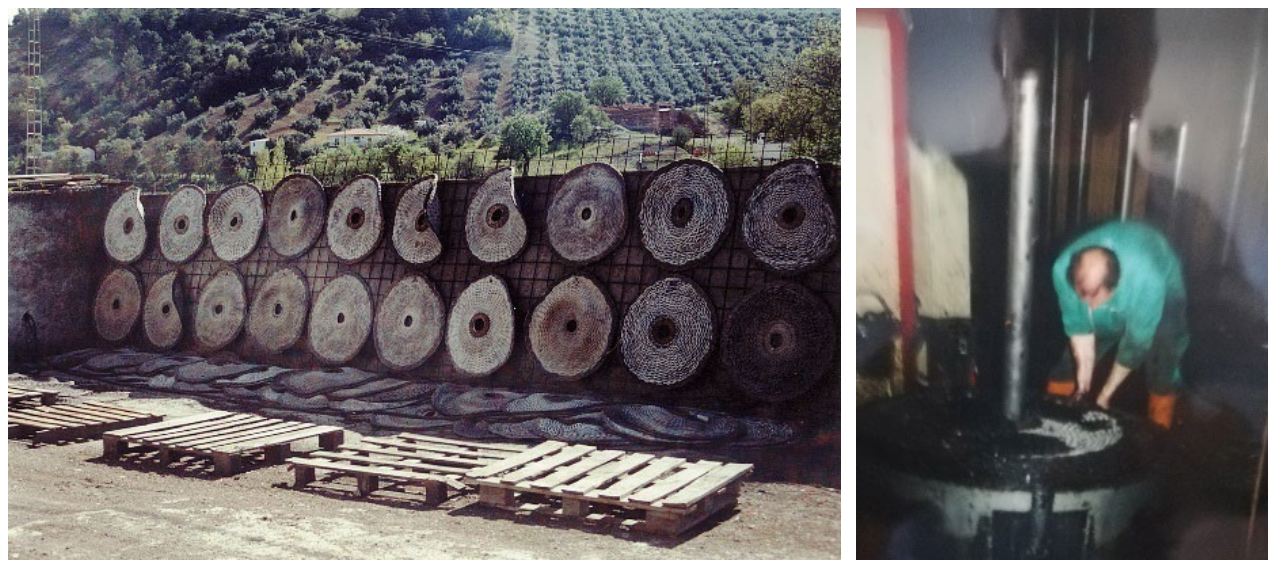

Figura 29-30. Confines o capachos. Cargo. (Fuente: Paco Peregrina Blanco).

formando DCOOP, pertenece a este grupo cooperativo que es el mayor productor mundial de aceite de oliva. También pertenece, desde su formación, a la Denominación de Origen «Poniente de Granada», que controla la producción de los mejores aceites que se producen en la zona del Poniente Granadino.

\subsection{Molino del cortijo de la Torre del Sol}

La aparición de dicho molino como tal es muy tardía, si bien en 1955 ya estaba en funcionamiento según se desprende del suplemento del periódico Patria, al que 
nos hemos referido anteriormente en varias ocasiones. En esta fecha se denominaba "Fabrica de Aceites Santa Teresa», siendo propiedad de don José Figueruela e hijos. Las características de la misma descritas por el sr. Figueruela eran empiedro de cuatro rulos, termo-filtro y prensa hidráulica de treinta centímetros de diámetro. La fuerza motriz utilizada era un motor de gas-oil de alrededor de veinte caballos de potencia y con capacidad de molturación de cuatro mil kg en ocho horas. La capacidad de almacenamiento de aceite era de cuarenta mil kg.

Esta fábrica pasó a don Francisco Figueruela Méndez a partir de 1967, que fabricó aceites con la denominación «Aceites Torre del Sol», pudiendo añadir poco más por el momento sobre las peculiaridades del mismo. Conocemos algunos montefrieños que trabajaron como cagarraches en este molino, el «Cartuchi», Francisco "Palomo», Francisco «El Pínchin», Juan y Francisco Chica, «Pizarro» (Guzmán, 2010).

Se ubicó en dependencias anejas al cortijo denominado Torre del Sol, que toma su nombre de una antigua atalaya cuyos restos se encuentran próximos al mismo y que fue propiedad de la familia Figueruela hasta hace pocos años. De este cortijo se tienen referencias desde 1581, año en que por "compussición» paso a ser de propiedad privada siendo su primer propietario Francisco de Aranda, yerno de Juan de Trillo, que lo había tenido usurpado a la Corona hasta esa fecha (Jiménez, 2009).

\section{A MODO DE CONCLUSIÓN: MOLINOS Y PROPIETARIOS}

Aunque ya hemos comentado en cada caso los propietarios de la industria del aceite en Montefrío conviene mencionar algunos datos sobre sus propietarios; vemos cómo predominan las familias de terratenientes o grandes propietarios que dominaban los recursos industriales en el municipio, al igual que las grandes propiedades desde su origen, algo parecido ocurre en el control y propiedad de los molinos hidráulicos ubicados en los principales cauces de los arroyos de Montefrío (Pedregosa y Jiménez, 2013, Pedregosa, 2017).

Entre finales del siglo XIX y hasta la década de 1940 los grandes propietarios del olivar existentes en Montefrío contaban con almazaras propias, pudiendo regular la capacidad de molturación, como vemos en la evolución de sus propietarios. «En cambio, los pequeños propietarios de olivar no contaban con molino, tenían que llevar las aceitunas a los molinos o almazaras existentes, esperando su turno para la molienda, dejando la aceituna en los trojes» (Infante, 2011, p. 282), teniendo que pagar la maquila, pago en espacie o dinero por la molienda, obteniendo un aceite de peor calidad.

Del listado de molinos y fábricas de aceite de 1940, de las 14 instalaciones oleícolas existentes, una gran parte pertenecieron a una de las familias más importantes de Montefrío, la familia García-Valdecasas, y a otras como los Alba, Fuensalida Vega, Guerrero, Pérez, Amor y Jurado o Lara entre otras. Pero sobre todas, destaca la familia 
García-Valdecasas, con sus distintas ramificaciones y matrimonios, que llegó a poseer, desde finales del siglo XVIII hasta bien entrado el siglo XX, un total de siete molinos, entre ellos los urbanos situados en calle de las Marquesas o Zanjón, calle Muro-Lucas Peña, callejón de Muro, Enrique Amat, y los del término municipal, en el campo los más cercanos a Montefrío como La Alcubilla, Las Angosturas y San Cristóbal, aunque este último en origen pertenecía a la familia Guerrero. En total más de un $40 \%$ de los molinos aceiteros documentados en Montefrío hasta 1950 fueron propiedad de los García-Valdecasas por alianzas matrimoniales, compra o herencias.

Otras familias tuvieron la propiedad de diversos molinos como el caso de la familia Fuensalida Vega que tuvo la posesión en diversos momentos del molino de San Cristóbal y el de La Cueva-Tranca (Enrea). El molino de las Talas propiedad de la familia Lara, o los molinos de la Fuente del Moral y La Alcubilla propiedad de los Alba, o el caso del molino del Perú que perteneció a la familia Muñoz y Jurado y el ubicado en el antiguo Convento de la orden de San Francisco, propiedad de la familia Amor y Jurado tras la desamortización del mismo.

El peso de la familia García Valdecasas en la industria aceitera era patente en los años 1940, como destaca Del Arco en su estudio:

El poder de las instituciones locales queda patente al favorecer a productores de aceite vinculados al poder municipal. Un ejemplo de ello lo tenemos en Montefrío, concretamente en 1939 el ayuntamiento de Montefrío advertía a Juan María García Valdecasas Moreno que en su fábrica se realizaban operaciones de compra-venta de aceituna, sin contar con la autorización de la Delegación de industria ni con el alta en la contribución industrial. Por aquel entonces, en la corporación municipal estaba Luis García Valdecasas Torres pariente del anterior. En esto contribuía el apoyo del régimen a determinadas capas sociales que controlaban el poder local de los municipios (Del Arco, 2005, pp. 289-291).

Durante la década de 1940 muchas de las almazaras y molinos de aceite tuvieron que cerrar como consecuencia del estraperlo, la carestía y la especulación, que provocaron la falta de aceituna en zonas con abundantes molinos (Del Arco, 2005, p. 286), como sería el caso de las Angosturas, Fuente del Moral, Turca o los Endrinales en el caso de Montefrío.

En los molinos aceiteros trabajaron muchos montefrieños como cagarraches, según se recoge en un estudio realizado por Guzmán (2010), donde menciona los operarios que trabajaron en algunos de los molinos y fábricas de aceite de Montefrío a lo largo de los años 1950, y que hemos mencionado en cada molino.

La evolución del olivar y la extensión del mismo, con una expansión en pequeñas parcelas junto con los nuevos procesos de molturación y prensado provocarán que los molinos vayan evolucionando. En origen estos, desde el siglo XVIII hasta finales del siglo XIX, tenían las características prensas de viga y para la molienda la piedra cilíndrica. A partir de 1860-1935 se introducirán cambios en los sistemas de 


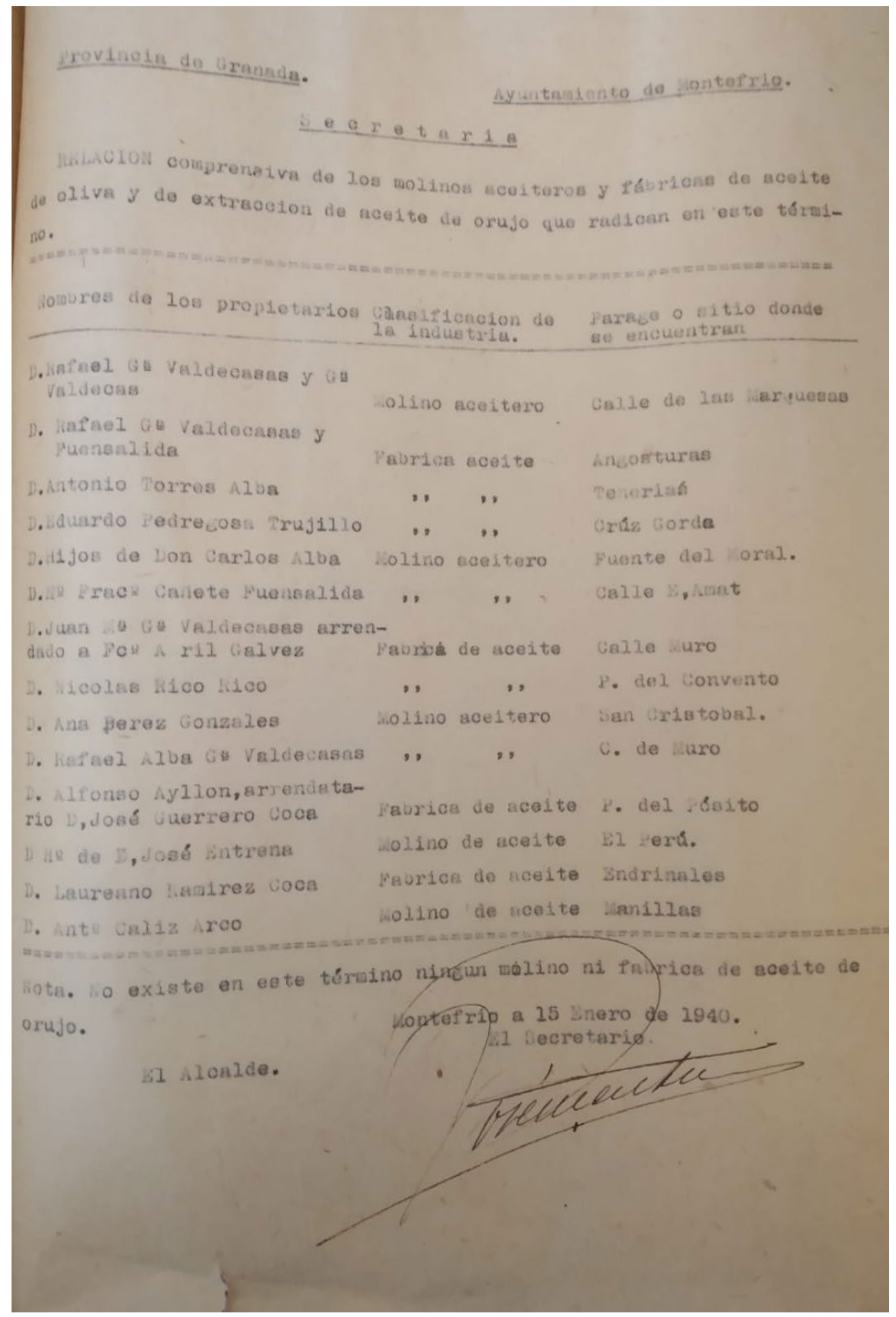

Figura 31. Relación de propietarios, molinos y fábricas de aceite en Montefrío en $1940^{1}$.

${ }^{1}$ AMM. 9.1.2. Miscelánea del sector agrario. Años 1941-1942. Declaración de reservas de aceite. Edicto del Ayuntamiento de Montefrío. 18 de octubre de 1940. 
molturación y prensado, adaptándose los molinos y fábricas a los nuevos adelantos. Así, se sustituirán las prensas de viga y torrecilla, por las de husillo y las prensas hidráulicas, a ello se unirá el cambio de la muela cilíndrica por los rulos troncocónicos, variando estos en número según la capacidad de molturación (2, 3 o 4). Además, la energía empleada en los molinos irá cambiando, frente a la de sangre movida por caballerías, irán apareciendo el uso del vapor, electricidad y gasoil, todos estos cambios los hemos observado en el análisis de los molinos de Montefrío, reduciéndose el tiempo del entrojado, mejorando la calidad de los caldos y reduciendo el tiempo de prensado y molturación, toda la evolución es recogida en la bibliografía especializada sobre el tema (Zambrana, 1987, pp. 136-145).

A lo largo de los años 60 del pasado siglo muchos de los molinos existentes hasta entonces se abandonan, prevaleciendo los mejor adaptados a la nueva época. En Montefrío seguirán en funcionamiento la Fábrica de Aceites de San Cristóbal, Aceites Torre del Sol, la Fábrica de Nuestra Señora la Virgen de los Remedios, y partir de 1967 surgirá un fenómeno de asociacionismo con la aparición de la cooperativa de San Francisco de Asís en el lugar del Jabonero, paraje con un nombre controvertido, ya que hay varias teorías al respecto; ya se conocía con este nombre en 1752 y parece que poco tuviera que ver con la elaboración de jabón, sino más bien con el color del terreno que recuerda al de la piel de los toros llamados «jaboneros», y que además se repite en otros municipios por esta misma razón (Jiménez, 2006). Si bien es cierto que en este municipio se sabe de la existencia de fábricas de jabón aprovechando los residuos del aceite.

\section{REFERENCIAS BILIOGRÁFICAS}

Archivo Municipal de Montefrío (AMM). 6.5.4 Impuestos Estatales Padrón de riqueza territorial. Caja 1, años 1884-1936.

AMM. 5.6. Padrón de habitantes de Montefrío, consulta diversos años 1834, 1838, 1845, 1848, 1854, 1867, 1910.

AMM. Sala A. 9.1.2. Miscelánea del sector Agrario. Declaración de reservas de aceite (1941-1942).

Registro de la Propiedad Montefrío. Notas simples sobre diversas fincas de Montefrío.

Birriel Salcedo, M. (2015). Tecnología, conocimiento y propiedad. Los molinos de aceite en el reino de Granada (S. XVIIII). Chronica Nova, 41, pp. 39-69. 
Del Arco Blanco, M. A. (2005). El primer franquismo en Andalucía Oriental (19361951). Poderes locales, instauración y consolidación del régimen franquista. Tesis Doctoral Universidad Granada. Recuperado el 10 de abril de 2020, de: https://digibug.ugr.es/handle/10481/807

Eslava Galán, J. (2004). Un jardín entre olivos. Barcelona: RBA Libros.

Gil Pérez, M.a D., Torres Hidalgo, M., Ramírez Moreno, N. (Coords.). (1991). Pósitos Cillas y tercias de Andalucía. Catálogo de Antiguas Edificaciones para Almacenamiento de Granos. Consejería de obras públicas y transportes. Sevilla: Dirección General de Arquitectura y Vivienda.

Gómez Oliver, M. (1983). La Desamortización de Mendizábal en Granada. Excma. Diputación Provincial Granada.

Guzmán Flores, J. (2010). Montefrío. Historia y vida de sus gentes años 50 y 60 . Granada.

Infante Amate, J. (2011). Ecología e historia del olivar andaluz. Un estudio socioambiental de la especialización olivarera en el sur de España. 1750-2000. Tesis Doctoral, Universidad Pablo Olavide, Sevilla, 2011. https://www.educacion. gob.es/teseo/imprimirFicheroTesis.do?idFichero=Wal5Sb07i7w\%3D

Infante Amate, J. (En revisión). El cultivo del olivar y su expansión en Montefrío desde 1752 hasta la actualidad.

Jiménez Comino, F: (2014). Instituciones de Seguridad y Protección Pública - La Guardia Civil en Montefrío. Manantial, 5, pp. 9-17.

JiménezComino,F.(2009).Procesosderevisióndetierrasbaldías. Apeos, composiciones y ventas 1581. http://es.calameo.com/read/001191095299681018bdd

Jiménez Comino, F. (2006). Las Cruces de Montefrío. http://www.montefrio.org/ impresos/cruces_montefrio.pdf

López Gálvez, M.a Y. (2013). Consideraciones técnicas acerca de los molinos aceiteros con prensas de torre 1750-1850. En 8 Congreso Internacional de Molinología 28, 29 y 30 de abril de 2012 (pp. 77-89). Tui (Pontevedra). 
López, M.a Y., Montes, F., Burgos, E., Moreno, A. (2012). Análisis tecnológicofuncional y arquitectónico de las almazaras cordobesas en la Edad Moderna. Separata ITEA, Información Técnica Económica Agraria, 108(3), pp. 312-342.

Madoz, P. (1848). Diccionario geográfico-estadístico e histórico de España y sus posesiones de ultramar. Tomo XI.

Martínez Enamorado, V. (2003). Al-Andalus desde la Periferia. La formación de una sociedad musulmana en tierras malagueñas (siglos VIII-X). Málaga: CEDMA.

Martínez Martín, M. (1995). Transformaciones liberares y cambio agrario en la Alta Andalucía. Tesis Doctoral. Inédita. https://digibug.ugr.es/handle/10481/14320

Moreno Vega, A., López Gálvez, M. a Y. (2017). Elaboración de aceites de oliva vírgenes. Madrid: Ediciones Mundi-Prensa.

Moreno Vega, A., López Gálvez, M. a Y. (2013). Del siglo XVI al XVIII en las almazaras cordobesas del sur: génesis, auge y declive de los grandes molinos ducales. En XIV Congreso de Historia Agraria, 2013, Badajoz 7-9 noviembre. http://seha. info/congresos/articulos/A.3.\%20Moreno\%20y\%20L\%C3\%B3pez.pdf

Oliver Pérez, M. D. (1993). El arabismo Alcoba y los topónimos Alcoba, Alcubillas, Cuba y Cubillas. Anuario de Lingüística Hispánica 9, pp. 165-194.

Padilla Mellado, L. L., Pedregosa Megías, R. J. (2013). Bienes y propiedades del Sacro Monte en la villa de Montefrío (Granada). Revista del Centro de Estudios Históricos de Granada y su Reino 25, pp. 313-345.

Pedregosa Megías, R. J., Jiménez Comino, F. (2013). Los molinos hidráulicos harineros de la Ribera de Mairena Montefrío (Granada). Datos históricos para su conocimiento: la arquitectura del Molino de Peinado o Fórtiz. En R. Vallejo Pousada, P. Torres Pérez, F. X. Lores Rosal (Eds.), Molinos Innovación y Ciencia en el Patrimonio Etnográfico. 8 congreso Internacional de Molinología (pp. 215-225). Pontevedra: Diputación de Pontevedra.

Pedregosa Megías, R. J., Martínez-Novillo Moya, A. (2007). El Convento de San Antonio, Montefrío (Granada). Estudio Histórico-Arqueológico a partir del análisis de las Estructuras Emergentes. Antiqvitas 18-19, pp. 237-263.

Pedregosa Megías, R. J. (2018): El antiguo hospicio de los monjes franciscanos en Montefrío: «La Máquina». Manantial, 9, pp. 3-7. 
Pedregosa Megías, R. J. (2017). Molinos hidráulicos ubicados fuera de la ribera de Mairena, Montefrío (Granada): Lorca, Alcubilla, Cañada Ámbar, Junco. Ingenios tradicionales. En Recurso de Futuro. 9 Congreso Internacional de Molinología (pp. 230-232). Murcia.

Pedregosa Megías, R. J. (2012). La evolución de una villa de frontera: Montefrío. Antecedentes, configuración y transformación tras la conquista castellana. Revista del Centro de Estudios Históricos de Granada y su Reino, 24, pp. 73-103.

Pedregosa Megías, R. J. (2010). Actividad Arqueológica Puntual en el Convento de San Antonio, Montefrío (Granada), Anuario Arqueológico de Andalucía, 2006, pp. 1349-1356. https://www.juntadeandalucia.es/export/drupaljda/Anuarioarqueologico/Anuario-2006/Granada.pdf

Peinado Santaella, R. G. (1997). Montefrío 1752. Según las respuestas generales del Catastro de Ensenada. Madrid: Alcabala del viento.

Pequeño y Muñoz Repiso, D. (2010). Nociones acerca de la elaboración de aceite de olivas. Reproducción facsímil, 1879. Valladolid: Editorial Maxtor.

Pizarro, S. (2015): La Almazara de las Laerillas. En AA. VV., La almazara de Las Laerillas Nigüelas. Patrimonio industrial del valle de Lecrín (pp. 58-82). Granada.

Sánchez Garre, R. (2018). El cofín. Fabricación y uso en las almazaras antiguas. Revista Velezana 36, pp. 354-389.

Turices Abarca, N., Zurita Povedano, E. (2003). Cortijos, haciendas y lagares. Arquitectura de las grandes explotaciones agrarias en Andalucía. Provincia de Granada. Consejería de Obras Públicas y transportes. Dirección General de Arquitectura y Vivienda.

Zambrana Pineda, J. F. (1987). Crisis y modernización del olivar. Ministerio Agricultura. Pesca y Alimentación. Secretaria General Técnica. 